\title{
Experimental investigation of cracking behaviors of ductile and brittle rock-like materials
}

\author{
Hao Bai, Wei Du* \\ Sichuan Expressway Construction \& Development Group Co., LTD, Chengdu, China \\ secdcbb@126.com \\ 582126107@qq.com
}

Yundong Shou*, Lichuan Chen

National Breeding Base of Technology and Innovation Platform for Automatic-monitoring of Geologic Haarards (Chongqing Engineering Research Center of Automatic Monitoring for Geological Hazards), Chongqing, China

Wuban University, China

shouyundong@wbu.edu.cn, bttps://orcid.org/0000-0001-7424-4006

chen_lichuan@163.com

Filippo Berto

Norwegian University of Science and Technology, Norway

filippo.berto@ntnu.no

ABSTRACT. The cracking characteristics of ductile rocks were studied by similar materials with sand, barite, epoxide resin, polyamide, silicone rubber and alcohol, while the cracking characteristics of brittle rocks were investigated by similar material with sand, barite, rosin and alcohol. In this paper, to enhance the application range of the rock-like materials in the field of geotechnical engineering model tests, the values of the elastic modulus and the compressive strength of the artificial rock-like materials are changed in a wide range by adjusting the amount of cementitious materials (epoxide resin, polyamide, rosin, etc). The elastic modulus, compressive strength and cracking characteristics were obtained from the complete axial stress-strain curves of the specimens made of similar materials, which were cast using the different mixture ratios. These experimental data can provide quantitative investigation on mixture ratios of similar materials of rocks to model the geotechnical engineering. Furthermore, the effect of mixture ratios on mechanical properties and crack propagation pattern of specimens were also investigated by the specimens with pre-existing flaws under uniaxial compressive tests.

KEYWORDS. Rock-like materials; Material composition; Ductility; Brittleness; Crack evolution.

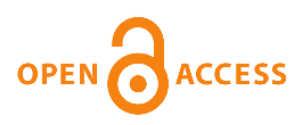

Citation: Bai, H., Du, W., Berto, F., Experimental investigation of cracking behaviors of ductile and brittle rock-like materials, Frattura ed Integrità Strutturale, 56 (2021) 16-45.

Received: 02.01.2021

Accepted: 17.01.2021

Published: 01.04.2021

Copyright: (C) 2021 This is an open access article under the terms of the CC-BY 4.0, which permits unrestricted use, distribution, and reproduction in any medium, provided the original author and source are credited. 


\section{INTRODUCTION}

$\mathrm{T}$ he similar simulation test in rocks on the basis of the similarity theory of modeling test is an explorative method to study the mechanical properties of geotechnical materials. The mechanical phenomena and the stress-strain variation characteristics of prototype are analyzed through the observation of stress and strain on similar models casted by using single or multiple materials, which provides a more reasonable scientific basis for the design of the geotechnical engineering and the selection of the construction scheme.

In similar model experimental studies, the ratio of similar materials and the casting method of test models have a great influence on the physical and mechanical properties of the material, which plays a decisive role in the success of similar simulation tests. For a long period of time, the geotechnical similar simulation test has been an important means of solving complex engineering problems. It can not only study the normal stress state of engineering, but also acquire the ultimate load and failure modes of engineering. Meanwhile, compared with the numerical calculation, the results given by similar simulation tests are more intuitive and can give people a deeper impression, and are widely used in geotechnical engineering research.

The cracking mechanisms of rocks have been studied experimentally on rock-like materials or rock materials, and rock-like materials are widely used because the flaws are easy to be fabricated. The first experimental study on rock-like specimens that contained flaws under uniaxial compression condition was conducted by Brace and Bombolakis [1]. Since then, many studies have examined the fracture processes of pre-cracked rock-like materials subjected to compression. Experimental studies have been performed on many different types of rock-like materials, including glass [2,3], Columbia Resin [4], polymethyl methacrylate [5,6], cement mortar [7], sandstone-like composite material [8-11], and gypsum [12-18]. To investigate the initiation, propagation, and coalescence of cracks in real rock materials, some experiments and numerical simulation on rock such as granite [19-21], marble [17-18,22] and mudstone [23] have also been conducted. Zhou et al. [24] and Bi et al. [25] proposed General Particle Dynamics to simulate the crack initiation, growth and coalescence in rock or rock-like materials. Wang et al. [26-27] developed the conjugated bond-based peridynamics to investigate the cracking behaviors in rock or rock-like materials. Zhou et al. [28-29] established micromechanics-based model to study the damage mechanism of rocks. Zhou et al.[30] investigated the initiation, growth and coalescence of 3D crack in rock-like rocks. the cracking behaviors in rock or rock-like materials. Zhou et al. [30] and Zhang et al. [31-34] studied progressive failure of brittle rocks with non-isometric flaws. Such rock-like materials and real rock materials have not only common characteristics for crack evolution, but also differences caused by the material properties, loading methods, and specimen geometry [3536].

Moreover, since rock is a very complex and anisotropic material whose mechanical properties vary widely, ranging from hard rock with very high mechanical properties to soft rock with very low mechanical properties [30-36]. However, there is scarce study on the cracking behaviors and mechanical properties of ductile and brittle rock-like materials.

To simulate different kinds of rock with a wide range of intensity variation, a new type of rock-like material with wideranging and stable mechanical properties must be developed. In this paper, the certain raw materials were selected according to the mechanical properties of ductile and brittle rocks and the mechanical laws of ductile and brittle rock-like materials were obtained by experimental analysis of materials with different ratios, which provides a reference for the ratio of rocklike materials in experiments. In addition, two rock-like materials were applied to crack propagation experiment, and the influence rules of different ratios of rock-like materials on crack propagation modes and mechanical properties of the specimens were obtained.

\section{EXPERIMENTAL STUDIES}

\section{Specimen preparation}

7 he composition of the raw materials used to make similar models can be basically divided into three categories according to their use: the first one is filling material acted as the skeleton, the second one is cementing material that plays a role in bonding, and the third one is auxiliary admixture served as regulation of physical and mechanical properties. In similar simulation experiments, in order to make the similar model satisfy requirements of the volumetric weight similarity ratio, it is more common to use barite, gypsum, sand, iron powder as the filling material. There are also many cementitious materials commonly used as bonding materials like gypsum, white latex, epoxide resin, polyamide, cement, rosin, etc. At the same time, for the purpose of adjusting the physical and mechanical properties of rock-like materials to better simulate the actual rock, it is essential to add additional auxiliary agents, such as silicone rubber, lime, 
neoprene, glycerin (humectant), borax (retarder) mica powder, softwood chips, etc. Furthermore, to make rock-like materials isotropic and homogeneous after hardening molding, it is also necessary to incorporate a certain amount of organic solvent, including frequently-used gasoline, engine oil, alcohol, etc. And its purpose is to dissolve organic substances such as silicone rubber, so that the components can be more uniformly mixed.

In this paper, the experiment was designed to prepare rock-like materials which could simulate ductile and brittle rocks. Initially some raw materials are selected as rock-like materials. After that tentative raw materials are added for trial matching. Eventually, the preparative rock-like materials are tested in uniaxial compression in order to figure out whether the full stress-strain curve of the rock-like materials is similar to the corresponding curve of actual rocks.

When simulating the raw material composition of ductile rock-like materials, it was finally decided to use sand and barite as filling materials. Moreover, epoxide resin and polyamide were used as cementitious materials, silicone rubber and rosin were used as auxiliary adjusting agents, and alcohol was used as organic solvent. The force-displacement curve of whole process in uniaxial compression test for ductile rock-like material is shown in Fig. 1. With regard to brittle rock-like materials, sand and barite were used as filling materials, rosin was used as cementitious material, silicone rubber, epoxide resin and polyamide were used as auxiliary adjusting agents, and alcohol was used as organic solvent. Fig. 1 and Fig. 2 are the force-displacement curve of whole process in uniaxial compression test for ductile and brittle rock-like materials, respectively.

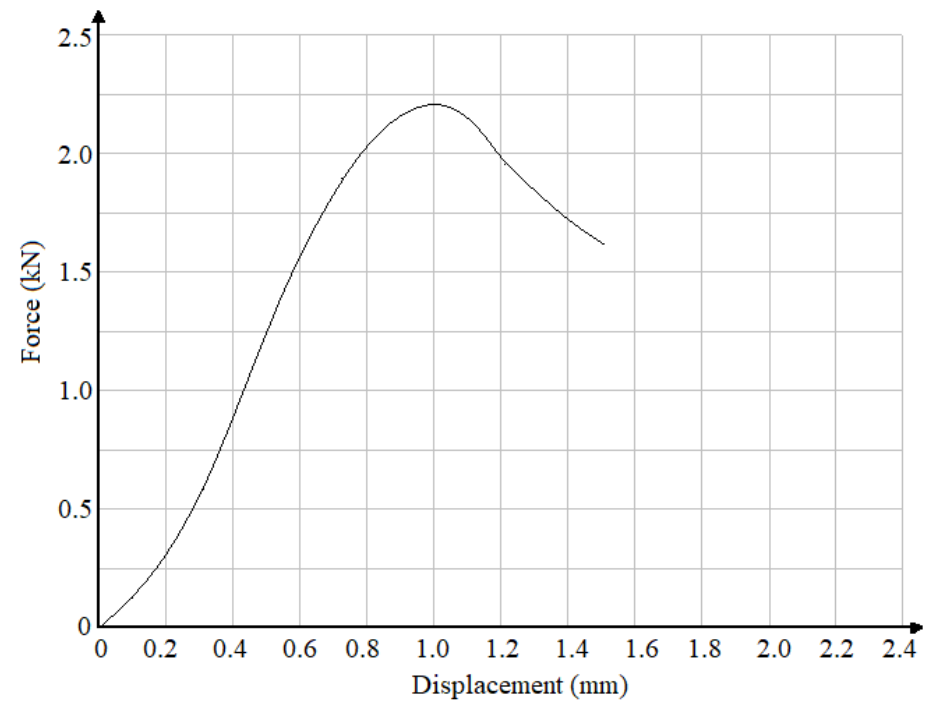

Figure 1: Force-displacement curve of the uniaxial compression UCS test for ductile rock-like materials.

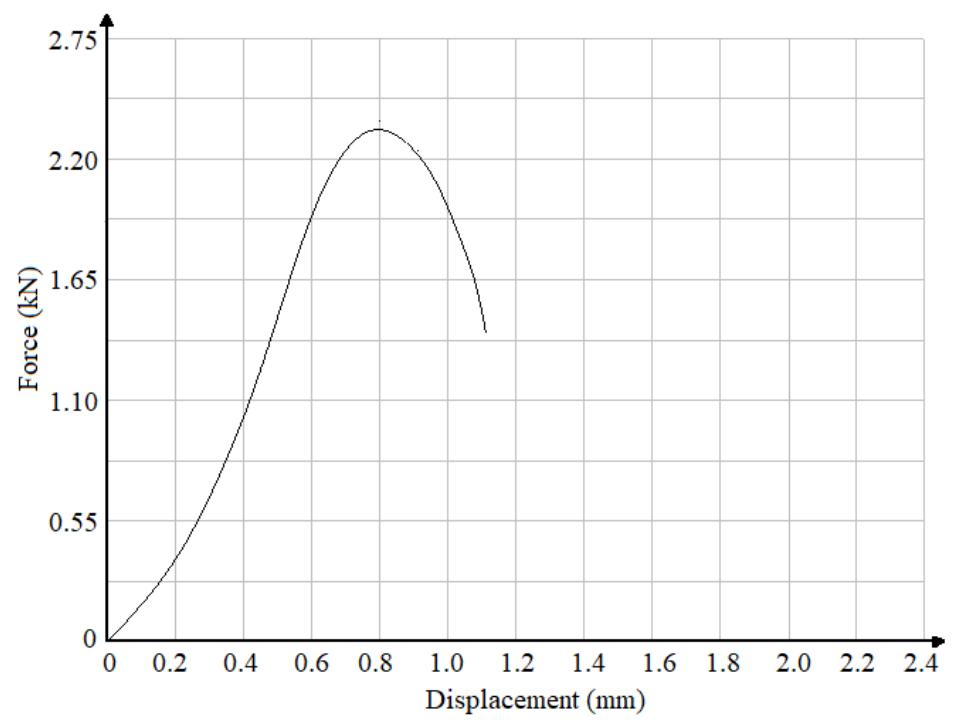

Figure 2: Force-displacement curve of UCS test for brittle rock-like materials. 
To obtain the experimental phenomena and make data reliable, two specimens for each ratio of materials were made and relevant test data was processed averagely. The ratio relationship of raw material is shown in Tabs. 1 and 2.

\begin{tabular}{|c|c|c|c|}
\hline Number & Raw materials & Weight ratio & $\begin{array}{l}\text { Percentage of variable } \\
\text { components }\end{array}$ \\
\hline A1 & Sand, barite, epoxy, polyamide and alcohol & 500:300:4:4:40 & $59 \%$ (sand) \\
\hline A2 & Sand, barite, epoxy, polyamide and alcohol & 600:300:4:4:40 & $63.3 \%$ (sand) \\
\hline A3 & Sand, barite, epoxy, polyamide and alcohol & 700:300:4:4:40 & $66.8 \%$ (sand) \\
\hline A4 & Sand, barite, epoxy, polyamide and alcohol & 800:300:4:4:40 & $69.7 \%$ (sand) \\
\hline B1 & Sand, barite, epoxy, polyamide and alcohol & 500:300:4:4:40 & $35.4 \%$ (barite) \\
\hline B2 & Sand, barite, epoxy, polyamide and alcohol & $500: 350: 4: 4: 40$ & $39 \%$ (barite) \\
\hline B3 & Sand, barite, epoxy, polyamide and alcohol & 500:400:4:4:40 & $42.7 \%$ (barite) \\
\hline B4 & Sand, barite, epoxy, polyamide and alcohol & $500: 450: 4: 4: 40$ & $45.1 \%$ (barite) \\
\hline $\mathrm{C} 1$ & Sand, barite, epoxy, polyamide and alcohol & 500:300:4:4:40 & $0.9 \%$ (epoxy and polyamide) \\
\hline $\mathrm{C} 2$ & Sand, barite, epoxy, polyamide and alcohol & 500:300:6:6:40 & $1.4 \%$ (epoxy and polyamide) \\
\hline C3 & Sand, barite, epoxy, polyamide and alcohol & $500: 300: 8: 8: 40$ & $1.9 \%$ (epoxy and polyamide) \\
\hline $\mathrm{C} 4$ & Sand, barite, epoxy, polyamide and alcohol & 500:300:10:10:40 & $2.3 \%$ (epoxy and polyamide) \\
\hline D1 & Sand, barite, epoxy, polyamide and alcohol & 500:300:4:4:40 & $0 \%$ (silicone rubber) \\
\hline D2 & $\begin{array}{c}\text { Sand, barite, epoxy, polyamide, alcohol and silicone } \\
\text { rubber }\end{array}$ & $500: 300: 4: 4: 40: 5$ & $0.6 \%$ (silicone rubber) \\
\hline D3 & $\begin{array}{c}\text { Sand, barite, epoxy, polyamide, alcohol and silicone } \\
\text { rubber }\end{array}$ & $500: 300: 4: 4: 40: 10$ & $1.2 \%$ (silicone rubber) \\
\hline D4 & $\begin{array}{c}\text { Sand, barite, epoxy, polyamide, alcohol and silicone } \\
\text { rubber }\end{array}$ & $500: 300: 4: 4: 40: 15$ & $1.7 \%$ (silicone rubber) \\
\hline E1 & Sand, barite, epoxy, polyamide and alcohol & $500: 300: 4: 4: 40$ & $0 \%$ (rosin) \\
\hline E2 & Sand, barite, epoxy, polyamide, alcohol and rosin & $500: 300: 4: 4: 40: 2$ & $0.2 \%$ (rosin) \\
\hline E3 & Sand, barite, epoxy, polyamide, alcohol and rosin & $500: 300: 4: 4: 40: 4$ & $0.5 \%$ (rosin) \\
\hline E4 & Sand, barite, epoxy, polyamide, alcohol and rosin & 500:300:4:4:40:6 & $0.7 \%$ (rosin) \\
\hline F1 & $\begin{array}{c}\text { Sand, barite, epoxy, polyamide, alcohol and silicone } \\
\text { rubber }\end{array}$ & $500: 300: 4: 4: 40: 5$ & $0 \%$ (rosin) \\
\hline $\mathrm{F} 2$ & $\begin{array}{l}\text { Sand, barite, epoxy, polyamide, alcohol silicone } \\
\text { rubber and rosin }\end{array}$ & $500: 300: 4: 4: 40: 5: 2$ & $0.2 \%$ (rosin) \\
\hline F3 & $\begin{array}{c}\text { Sand, barite, epoxy, polyamide, alcohol silicone } \\
\text { rubber and rosin }\end{array}$ & $500: 300: 4: 4: 40: 5: 4$ & $0.5 \%$ (rosin) \\
\hline F4 & $\begin{array}{l}\text { Sand, barite, epoxy, polyamide, alcohol silicone } \\
\text { rubber and rosin }\end{array}$ & $500: 300: 4: 4: 40: 5: 6$ & $0.7 \%$ (rosin) \\
\hline
\end{tabular}

Table 1: The raw materials and ratio of ductile rock-like materials.

In the process of fabricating specimens, the raw materials were first weighed according to the ratio of each rock-like materials. At the same time, the mold was cleaned and assembled, and the inner surface of the mold was coated with an appropriate amount of lubricating oil so that the mold could be removed later. Subsequently the sand and barite powder were mixed evenly, and the rosin powder or the epoxide resin-polyamide was dissolved in alcohol to form an alcohol solution (which was thoroughly stirred and slightly heated with hot water to accelerate dissolution), then the alcohol solution was then added evenly to the already mixed mixture. Since silicone rubber was not easily dissolved in alcohol, it could only be slowly dispersed in the agitated material during agitation. Finally, the mixture was poured into the mold and tamped (the hammer was stopped when there was no obvious sinking during the hammering process). The specimens after pouring molding is shown in Fig. 3. 


\begin{tabular}{|c|c|c|c|}
\hline Number & Raw materials & Weight ratio & $\begin{array}{l}\text { Percentage of variable } \\
\text { components }\end{array}$ \\
\hline A1' & Sand, barite, rosin and alcohol & 200:200:5:15 & $47.6 \%$ (sand) \\
\hline $\mathrm{A} 2^{\prime}$ & Sand, barite, rosin and alcohol & $250: 200: 5: 15$ & $53.2 \%$ (sand) \\
\hline A3' & Sand, barite, rosin and alcohol & $300: 200: 5: 15$ & $57.7 \%$ (sand) \\
\hline A4' & Sand, barite, rosin and alcohol & $350: 200: 5: 15$ & $61.4 \%$ (sand) \\
\hline B1' & Sand, barite, rosin and alcohol & $200: 200: 5: 15$ & $47.6 \%$ (barite) \\
\hline B2' & Sand, barite, rosin and alcohol & $200: 250: 5: 15$ & $53.2 \%$ (barite) \\
\hline B3' & Sand, barite, rosin and alcohol & $200: 300: 5: 15$ & $57.7 \%$ (barite) \\
\hline B4' & Sand, barite, rosin and alcohol & $200: 350: 5: 15$ & 61.4\% (barite) \\
\hline $\mathrm{C} 1^{\prime}$ & Sand, barite, rosin and alcohol & $200: 200: 5: 15$ & $1.2 \%$ (rosin) \\
\hline $\mathrm{C} 2^{\prime}$ & Sand, barite, rosin and alcohol & $200: 200: 7: 15$ & $1.7 \%$ (rosin) \\
\hline $\mathrm{C} 3^{\prime}$ & Sand, barite, rosin and alcohol & 200:200:9:15 & $2.1 \%$ (rosin) \\
\hline $\mathrm{C} 4^{\prime}$ & Sand, barite, rosin and alcohol & 200:200:11:15 & $2.6 \%$ (rosin) \\
\hline D1' & Sand, barite, rosin and alcohol & $200: 200: 5: 15$ & $0 \%$ (epoxy and polyamide) \\
\hline $\mathrm{D} 2^{\prime}$ & Sand, barite, rosin, alcohol, epoxy and polyamide & $200: 200: 5: 15: 1: 1$ & $0.47 \%$ (epoxy and polyamide) \\
\hline D3' & Sand, barite, rosin, alcohol, epoxy and polyamide & $200: 200: 5: 15: 2: 2$ & 0.94\% (epoxy and polyamide) \\
\hline D4' & Sand, barite, rosin, alcohol, epoxy and polyamide & $200: 200: 5: 15: 3: 3$ & $1.4 \%$ (epoxy and polyamide) \\
\hline E1' & Sand, barite, rosin and alcohol & $200: 200: 5: 15$ & $0 \%$ (silicone rubber) \\
\hline $\mathrm{E} 2^{\prime}$ & Sand, barite, rosin, alcohol and silicone rubber & 200:200:5:15:2 & $0.47 \%$ (silicone rubber) \\
\hline E3' & Sand, barite, rosin, alcohol and silicone rubber & 200:200:5:15:4 & $0.94 \%$ (silicone rubber) \\
\hline E4' & Sand, barite, rosin, alcohol and silicone rubber & 200:200:5:15:6 & $1.4 \%$ (silicone rubber) \\
\hline
\end{tabular}

Table 2: The raw materials and proportion of brittle rock-like material.

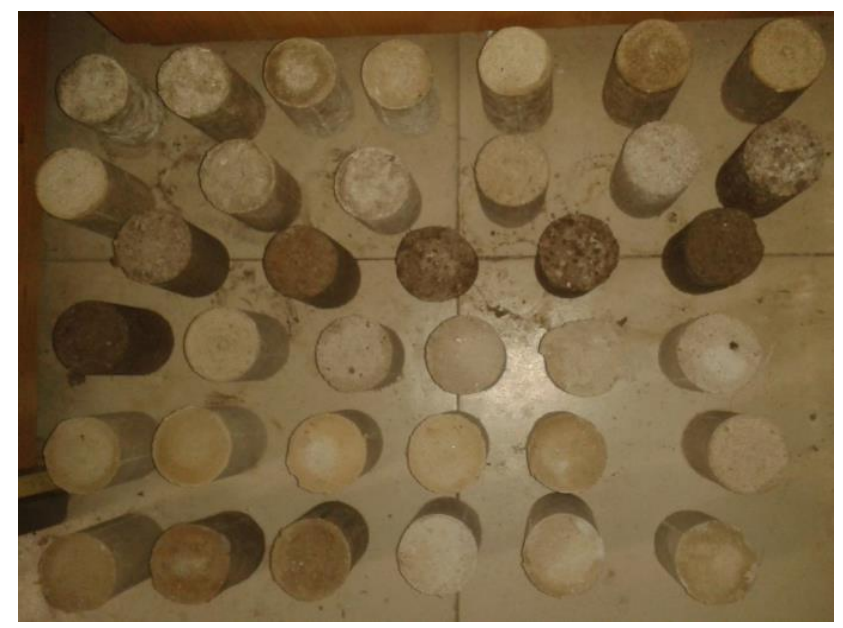

Figure 3: Prepared specimens. 
Testing System

In this paper, an electronic universal testing machine was used to carry out the uniaxial compression test of specimens. The test machine has two loading modes (load control and displacement control) which can automatically collect data throughout the test. In order to prevent the damage of the test machine caused by the sudden destruction of specimen and to ensure integrity of the stress-strain curve obtained by experiments, the loading mode of displacement control was selected in the experiments. The device used for testing the fracture toughness of rock-like materials consists of a loading device (electronic universal testing machine) and a bracket device (for supporting cylindrical specimens to meet the three-point bending loading requirements).

In the process of processing the specimen, $1 \mathrm{~mm}$ wide crack was first machined on the specimen, then the crack tip was ground with a diamond wire saw to a diameter of $0.5 \mathrm{~mm}$. In the test, the crack length is $10 \mathrm{~mm}$ (generally, the ratio of the crack length to the specimen diameter is 0.15 to 0.5 ), and the crack tip angle is $30^{\circ}$ (the crack tip angle is generally required to be small enough to produce a relatively strong I-type stress filed), the ratio of span to diameter is 1.5 (the ratio of span and diameter of the specimen is relatively small when the material strength is low, generally 1.5 to 4 ). After the specimen was processed, the specimen was placed in the exact position of the test holder and was tested under loading by the electronic universal testing machine. During the loading process, the crack propagation and failure modes of the specimen were observed and recorded, and finally the maximum load at the time of crack propagation was recorded. The crack geometry and loading diagram of the specimen are shown in Fig. 4.

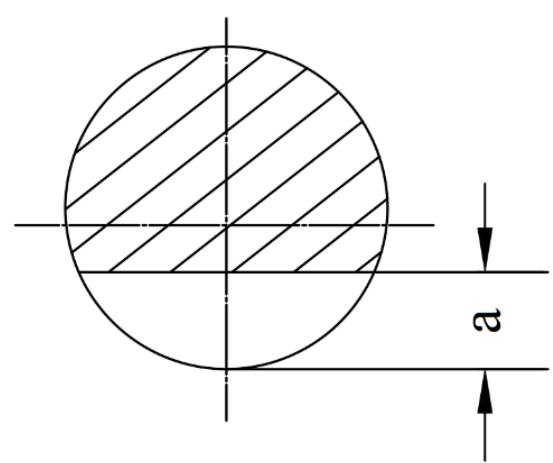

Figure 4: Crack geometry and loading schematic.

\section{ANALYSIS OF EXPERIMENT RESULTS}

\section{Analysis of experimental results of ductile rock-like materials}

Effect of raw materials on stress-strain curves and brittleness indexes of ductile rock-like materials

enerally, the complete stress-strain curve of rocks can be used to qualitatively analyze the brittleness of rock.

Therefore, based on the brittleness index of the full stress-strain curve, another brittleness index, namely "brittle modulus", is obtained. Eqn. (1) is the calculation expression of the brittle modulus.

$$
E_{0}=\frac{\sigma_{c}-\sigma_{0}}{\varepsilon_{0}-\varepsilon_{c}}
$$

were

$E_{0}$ is the brittle modulus,

$\sigma_{c}$ is peak strength,

$\sigma_{0}=\sigma_{c}+\sigma_{1} / 2, \varepsilon_{0}$ is the strain corresponding to $\sigma_{0}$,

$\varepsilon_{c}$ is the strain corresponding to $\sigma_{c}$.

Fig. 5 and Fig. 6 are respectively diagrams of the stress-strain curves and brittle modulus changes of ductile rock-like materials under different raw material ratios. Combining the failure process of the specimen and analyzing the curve change in the figure, it can be seen that: 
(1) when the amount of sand increases, the difference in the damage of the specimen is little. The reason may be that a large amount of cementitious material and barite has a certain ductility when the sand content is low, and the shear failure of the sand also has a certain ductility when the sand content is high.

(2) When the barite content is relatively low, the specimen exhibits a certain ductility, and as the barite content increases, the ductility of the specimen is more pronounced. The reason is probably due to the fact that the cementitious materials, epoxide resin and polyamide, have a certain ductility, and the barite material itself also has good ductility when it is failed. When the barite content is relatively high, the specimen is mainly failed by the shear failure of sand and barite, and the barite itself has better ductility when it is failed.

(3) When the content of epoxide resin and polyamide is relatively low, the specimen has a certain ductility, and as the content of epoxide resin and polyamide increases, the ductility of the specimen is more obvious. The reason should be that the cementitious materials, epoxide resin and polyamide, have good ductility when they are dried and hardened.

(4) When the silicone rubber is not added, the specimen has a certain ductility, and the ductility of the specimen is more obvious as the amount of added silicone rubber increases. The reason is that the silicone rubber after coagulation hardening has a good ductility, which increases the ductility of the specimen.

(5) In the absence of silicone rubber, when the amount of rosin is 0 , the specimen exhibits certain ductile failure properties, and as the amount of added rosin increases, the specimen no longer has good ductility, but exhibits brittle failure properties. The reason should be that the hardened rosin exhibits a distinct brittle character when it is failed, and ultimately changes the ductile failure properties of rock-like material itself. 6Under the condition of containing silicone rubber, when the amount of rosin is 0 , the specimen also exhibits certain ductile failure properties, and as the amount of added rosin increases, the ductility of the specimen is not severely reduced. But only when the rosin is added in a large amount, the ductility of specimen is slightly reduced. The reason should be that rock-like materials added with silicone rubber without rosin have good ductility, and the addition of a small amount of rosin is not sufficient to change their ductility.

It can also be seen from figures that:

(1) As the amount of sand decreases, the strain corresponding to the maximum stress tends to increase, which may be related to the strain of epoxide resin and polyamide after hardening. With the decrease of sand content, the residual strength of rock-like materials tends to increase, which may be due to the high residual strength of both epoxy and polyamide, as well as barite.

(2) As the barite content increases, there are some differences in the residual strength of rock-like materials. This is most likely due to the high residual strength of both epoxy and polyamide, as well as barite.

(3) As the content of epoxide resin and polyamide increases, the strain corresponding to the maximum stress tends to increase slightly, because epoxide resin and polyamide will have a larger strain when broken. Moreover, the residual strength of the specimen tends to increase when the content of epoxide resin and polyamide is high, because epoxide resin and polyamide also have high residual strength.

(4) When the amount of added silicone rubber increases, the residual strength of the specimen slightly decreases, which is likely to be related to the high residual strength of the silicone rubber.

(5) As the amount of rosin added increases, the strain corresponding to the maximum stress tends to decrease, which may be related to the less strain of the rosin. In the absence of silicone rubber, the residual strength of the specimen does not change substantially when the amount of added rosin changes. In the case of silicone rubber, the residual strength of the specimen slightly changes when the amount of rosin added increases, which may be related to the high residual strength of rock-like materials without rosin.

\section{Effect of raw materials on stress-strain curves and brittleness indexes of ductile rock-like materials}

The elastic modulus can be obtained by the stress-strain curve of rock-like material. Fig. 7 shows the relationship between the content of each raw material and the elastic modulus.

It can be clearly seen from the Fig. 7 that the elastic modulus of the ductile rock-like material can be increased by increasing the content of epoxide resin and polyamide, and adding an appropriate amount of rosin. The elastic modulus of rock-like materials increases when rosin is added, which may have a great relationship with the elastic modulus of rosin.

In the experiment, when the amount of sand and barite powder in the raw material component cannot be changed, the purpose of lowering the elastic modulus of the material can be achieved by adding the auxiliary admixture silicone rubber. From the effect of the raw material on the stress-strain curve, it can be known that if the elastic modulus of the ductile rocklike material is to be enhanced and the ductile rock-like material has a certain brittleness, the epoxide resin and polyamide should not be added excessively, but an appropriate amount of the auxiliary regulator rosin should be added. 

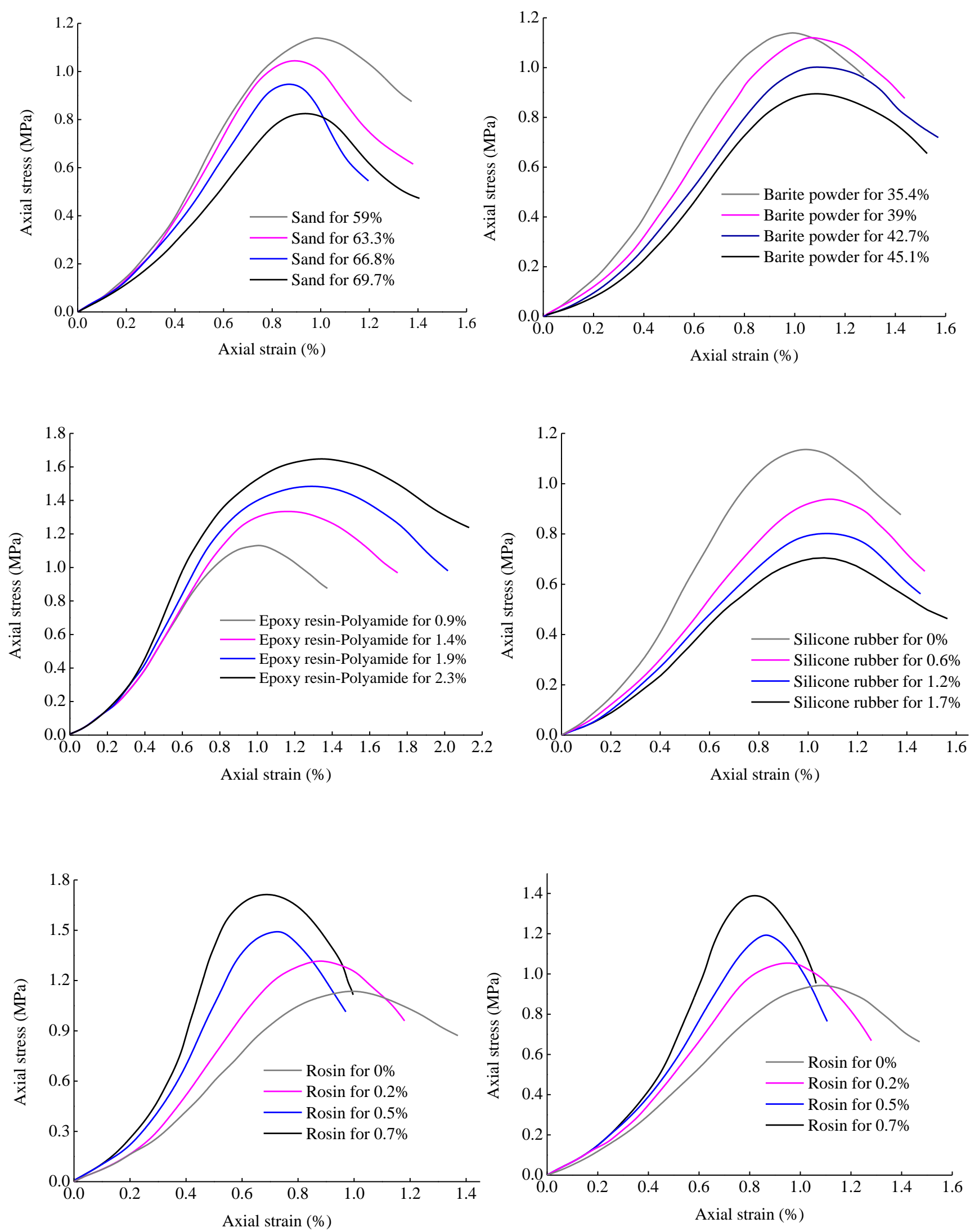

Figure 5: Stress-strain curve of ductile rock-like materials with different raw material ratios. 

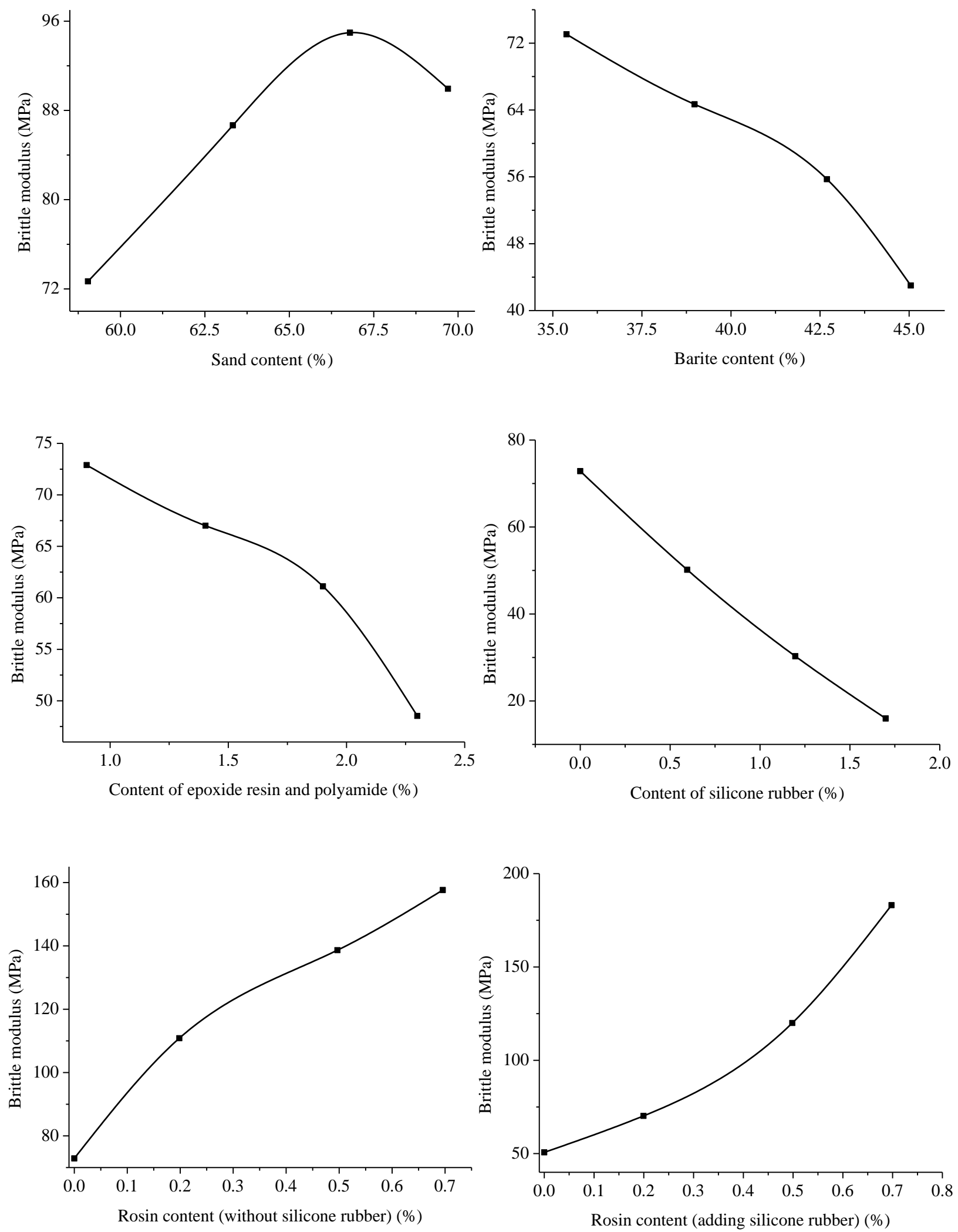

Figure 6: Brittle modulus of ductile rock-like materials with different raw material ratios. 

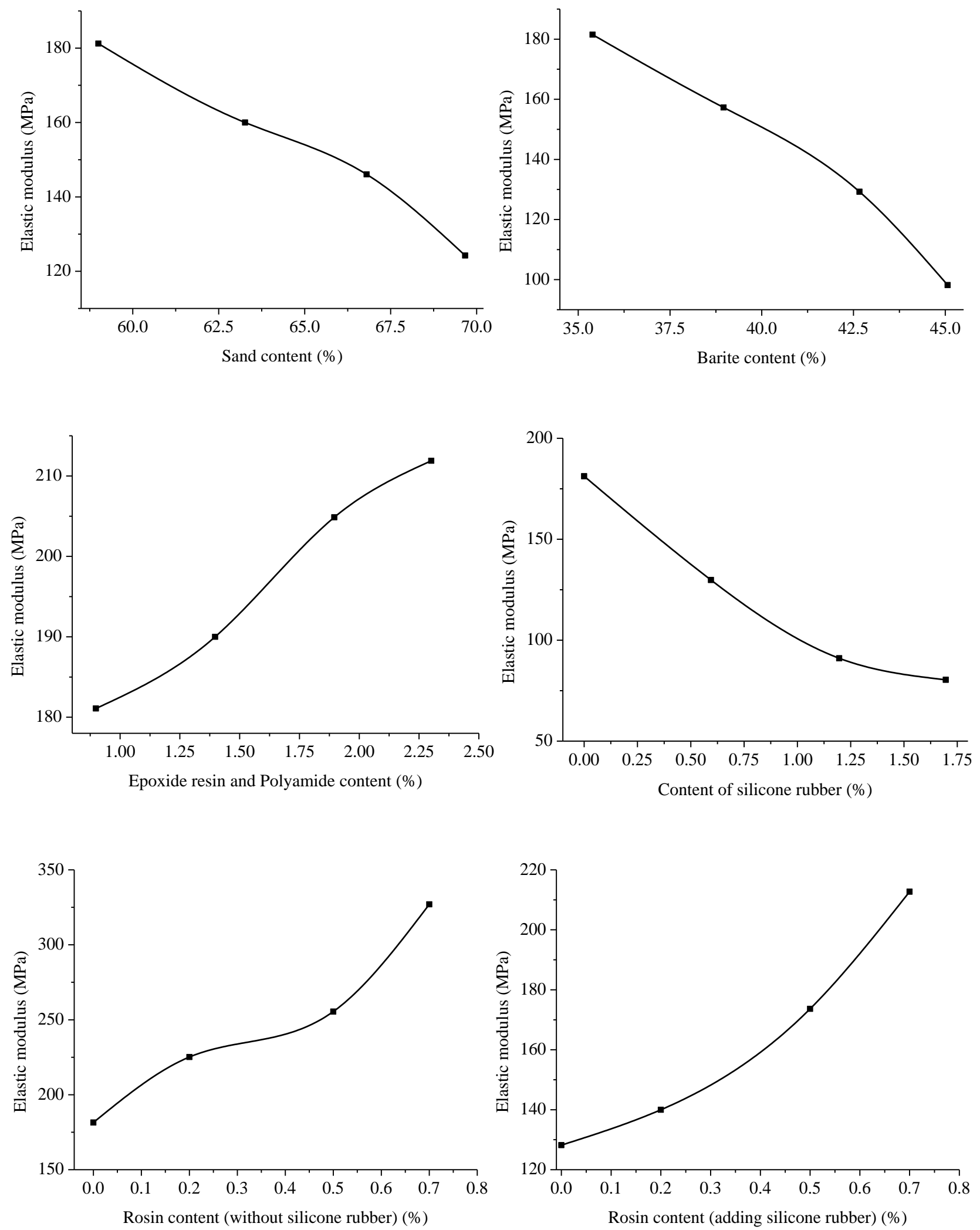

Figure 7: Relations between raw materials contents and elastic modulus of ductile rock-like materials. 

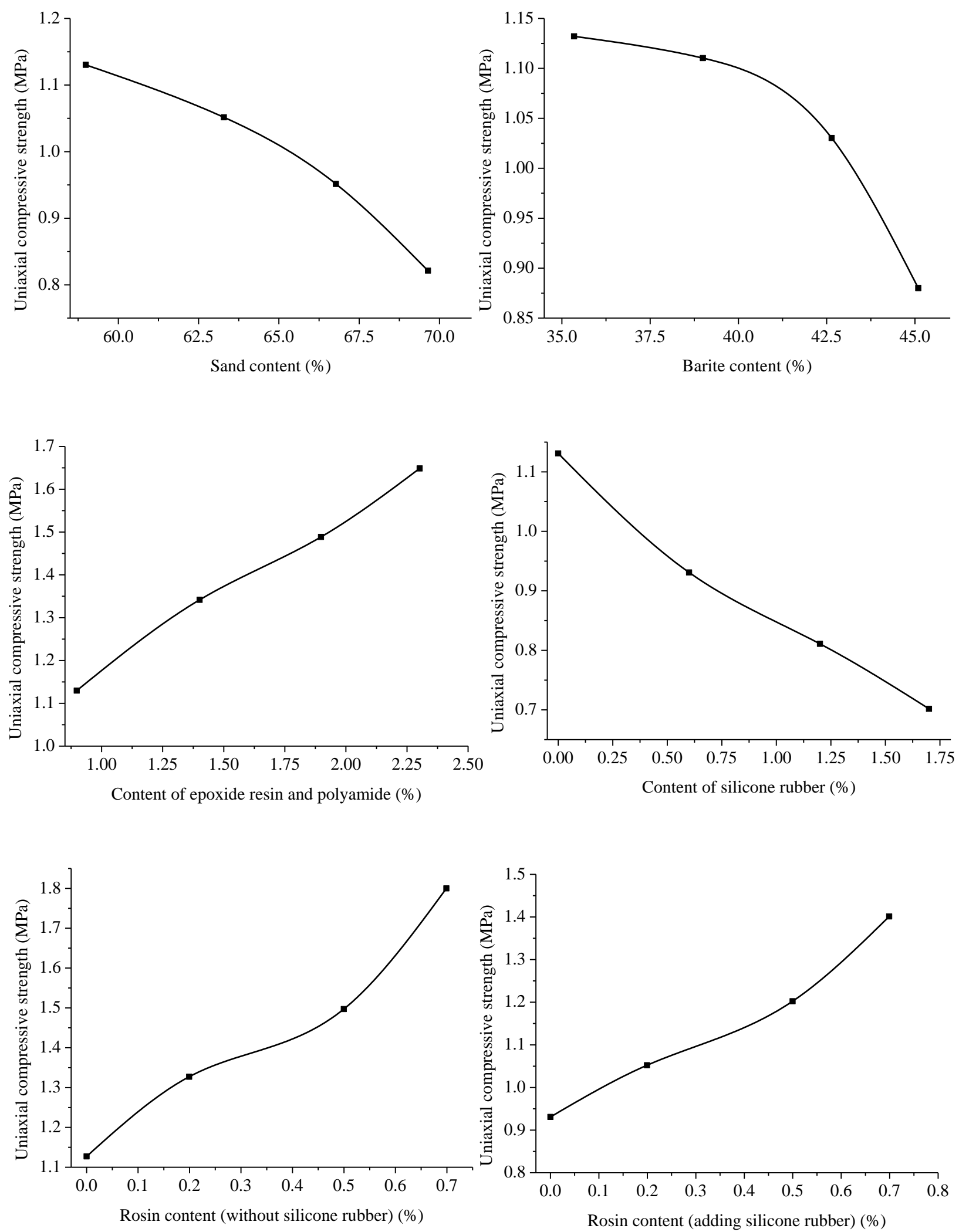

Figure 8: Relationships between raw materials contents and uniaxial compressive strength of ductile rock-like materials. 
Effect of raw materials on uniaxial compressive strength of ductile rock-like materials

The uniaxial compressive strength of the rock-like materials, that is, the peak stress on the curve, can be obtained by the stress-strain curve. Fig. 8 shows the relation between the content of each raw material and the uniaxial compressive strength. It can be clearly seen from Fig. 8 that the uniaxial compressive strength of ductile rock-like materials can be enhanced by increasing the content of epoxide resin and polyamide and adding an appropriate amount of the auxiliary regulator rosin. To reduce the uniaxial compressive strength of ductile rock-like materials, it is possible to increase the content of sand and barite, and to add an appropriate amount of auxiliary regulator silicone rubber.

In the experiment, when the content of sand and barite powder cannot be changed, the purpose of reducing the uniaxial compressive strength of the ductile rock-like material can be achieved by adding the auxiliary admixture silicone rubber. From the effect of the raw material on the stress-strain curve, it can be known that if the uniaxial compressive strength of the ductile rock-like material is to be enhanced and the ductile rock-like material has a certain brittleness, the epoxide resin and polyamide cannot be excessively added, but an appropriate amount of the auxiliary regulator rosin should be added.

\section{Effect of raw materials on fracture toughness of ductile rock-like materials}

Referring to the relevant literature [37], the formula for fracture toughness of rock-like materials is shown in Eqns. 2 and 3.

$$
K_{\text {IC }}=\frac{P S \sqrt{a}}{D(D-a)^{2}}\left[3.75-11.98 \frac{a}{D}+24.4\left(\frac{a}{D}\right)^{2}-25.69\left(\frac{a}{D}\right)^{3}+10.02\left(\frac{a}{D}\right)^{4}\right]
$$

where $\mathrm{P}$ represents the maximum load at the time of loading, $\mathrm{S}$ is the span, $\mathrm{D}$ denotes the diameter, which is $0.05 \mathrm{~m}$, and a is the crack length, which is $0.02 \mathrm{~m}$.

Substituting a and D into Eqn. 2 yields

$$
K_{I C}=2675 P S(P a \cdot \sqrt{\mathrm{m}})
$$

By substituting relevant experimental data into Eqn. 3, the fracture toughness of ductile rock-like materials can be obtained. The relationship between the fracture toughness and the content of each raw material is shown in Fig. 9.

It can be clearly seen from Fig. 9 that the fracture toughness of ductile rock-like materials can be enhanced by increasing the content of epoxide resin and polyamide and adding an appropriate amount of auxiliary regulator rosin. At the same time, it can be seen that for the purpose of improving the fracture toughness of rock-like materials, the addition of silicone rubber and rosin is not as good as the case of adding rosin alone. To reduce the fracture toughness of ductile rock-like materials, the content of sand and barite can be increased, and an appropriate amount of auxiliary regulator silicone rubber can be added.

In the experiment, when the content of sand and barite powder cannot be changed, the purpose of reducing the fracture toughness of the ductile rock-like material can be achieved by adding the auxiliary admixture silicone rubber. From the effect of the raw material on the stress-strain curve, it is also known that if the fracture toughness of the ductile rock-like material is to be improved and the ductile rock-like material has a certain brittleness, the epoxide resin and polyamide should not be excessively added, but an appropriate amount of the auxiliary regulator rosin should be added.

\section{Analysis of experimental results of brittle rock-like materials}

Effect of raw materials on stress-strain curves and brittleness indexes of brittle rock-like materials

The uniaxial compressive stress-strain curve and brittle modulus of brittle rock-like materials can be obtained by the same treatment method. Fig. 10 and Fig. 11 show respectively stress-strain curves and brittle modulus changes for brittle rocklike materials at different raw material ratios.

It can be seen from the curves in the figures:

(1) When the sand content is relatively low, the specimen exhibits relatively brittle fracture properties, and the brittle fracture characteristics of the specimen are no longer obvious as the sand content increases. Because when the sand content is low, the damage of the specimen is mainly the brittle failure of the rosin. When the sand content is relatively high, the specimen is mainly failed by the shear failure of the sand. In addition, it can be seen that as the sand content increases, the strain corresponding to the maximum stress tends to increase. 

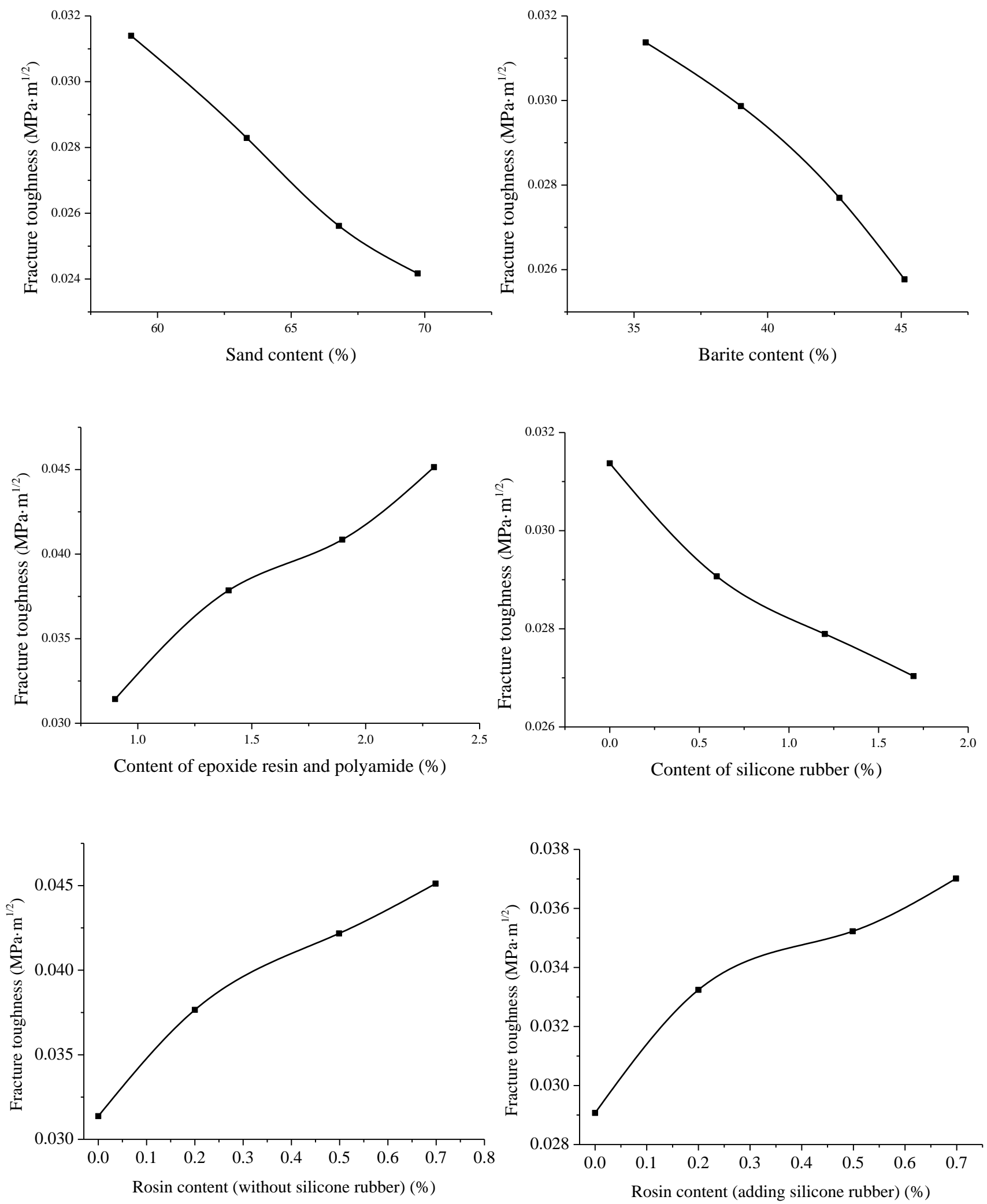

Figure 9: Relationships between raw materials contents and fracture toughness of ductile rock-like materials. 

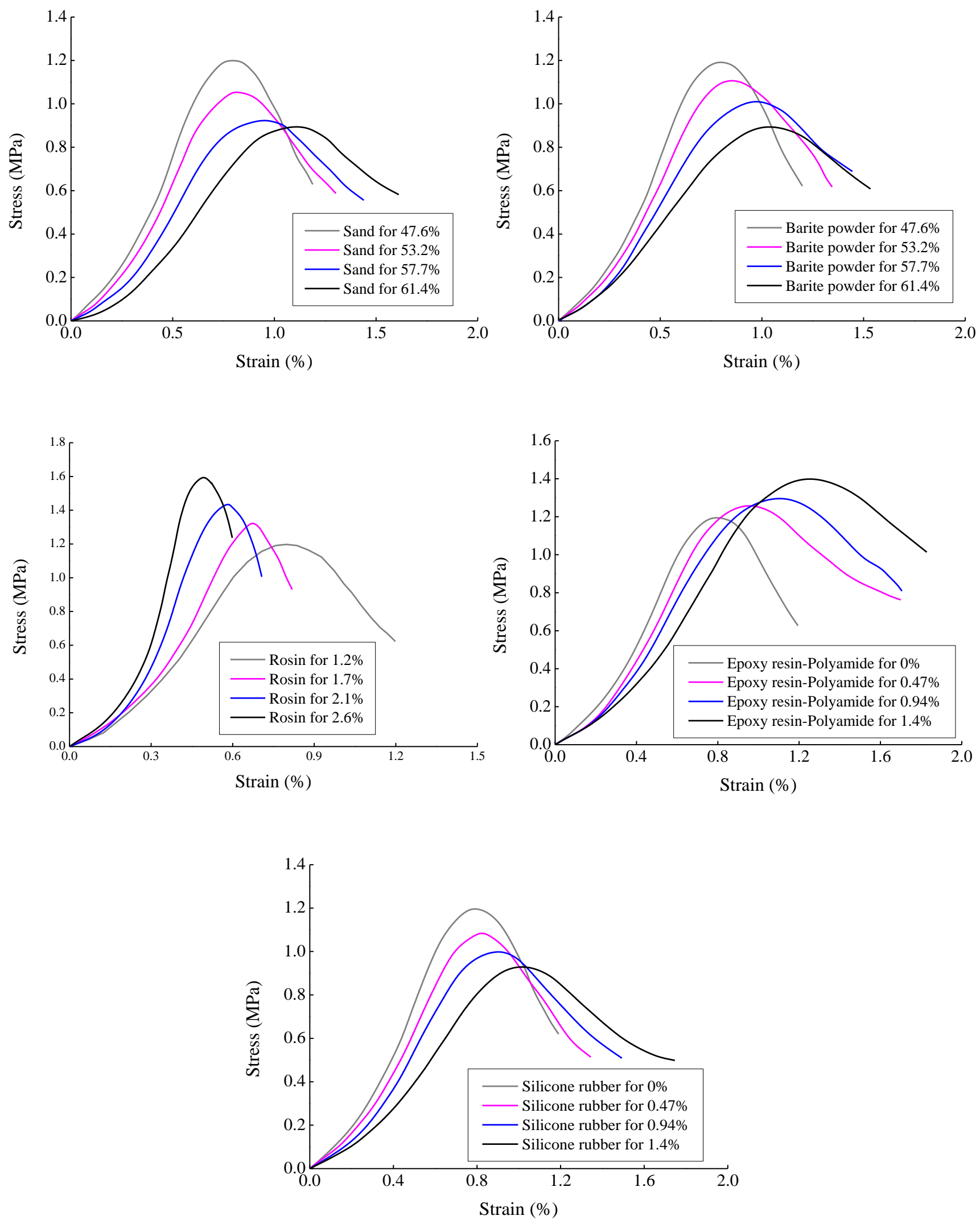

Figure 10: Stress-strain curve of brittle rock-like materials with different raw material ratios. 

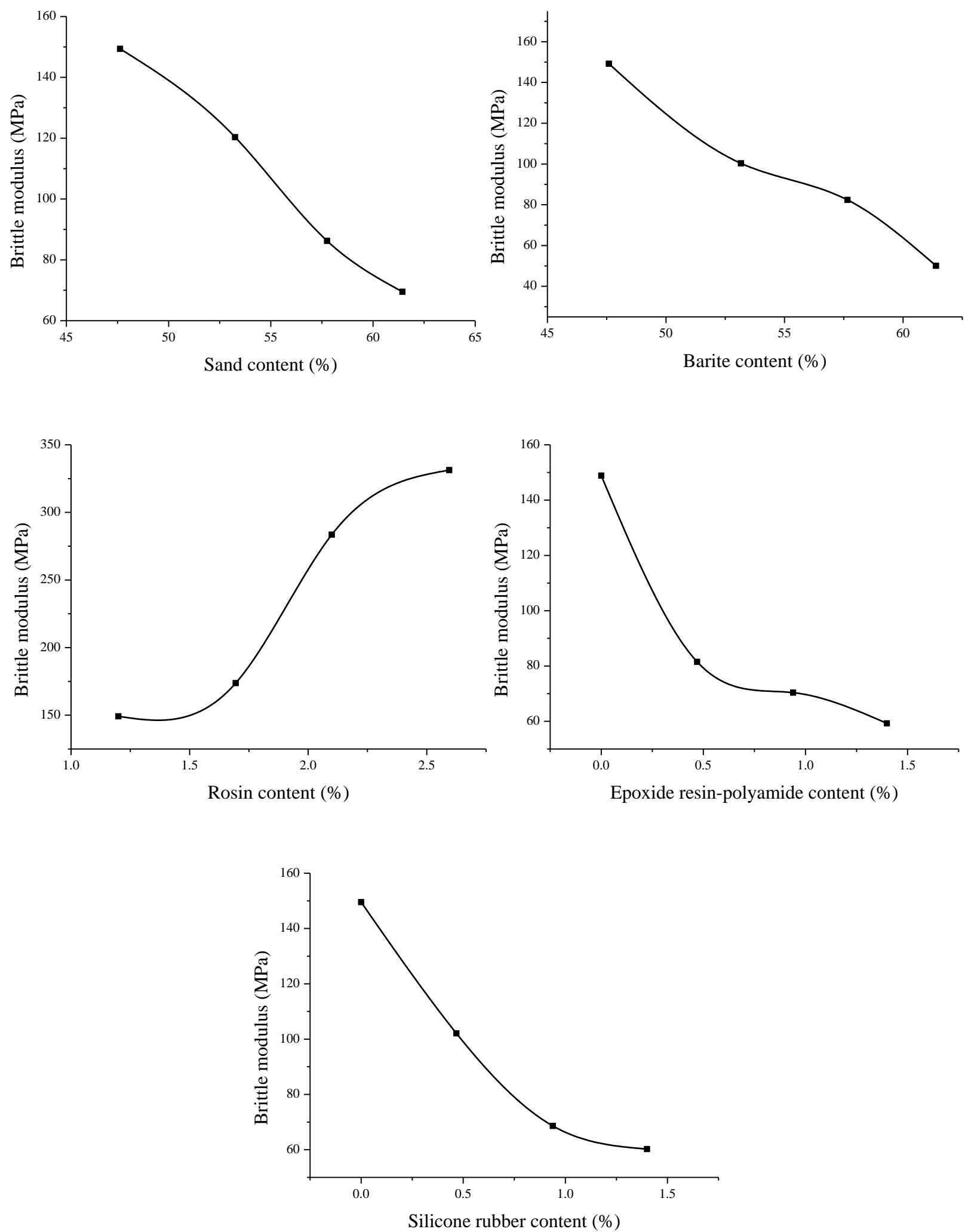

Figure 11: Brittle modulus of brittle rock-like materials with different raw material ratios. 
(2) When the barite content is relatively low, the specimen exhibits relatively obvious brittle fracture properties. With the increase of barite content, the brittle fracture characteristics of the specimen are no longer obvious. This is because when the barite content is relatively low, the damage of the specimen is mainly the brittle failure of the rosin. When the barite content is relatively high, the damage of the specimen is mainly reflected by the shear failure of sand and barite, and the barite material itself has relatively good ductility. It can also be found that as the barite content increases, the strain corresponding to the maximum stress tends to increase.

(3) When the content of rosin is relatively high, the specimen exhibits obvious brittle fracture properties, and the brittle fracture characteristics of the specimen are no longer obvious with the decrease of rosin content. This is also because when the rosin content is relatively high, the damage of the specimen is mainly the brittle failure of the rosin. When the content of rosin is relatively low, the damage of the specimen is mainly reflected by the shear failure of sand and barite, and the barite itself has better ductility. It can be seen that as the amount of added epoxide resin and polyamide increases, the strain corresponding to the maximum stress tends to increase, which may be related to the greater strain of epoxide resin and polyamide during failure. Moreover, it can also be seen that as the content of epoxide resin and polyamide increases, the residual strength of the specimen increases, which may be related to the good ductility of epoxide resin and polyamide.

(4) When rock-like materials do not contain the epoxide resin and polyamide, the specimen exhibits relatively obvious brittle fracture properties, and the brittle fracture characteristics of the specimen are no longer obvious as the amount of epoxide resin and polyamide added increases. The reason may be that epoxide resin and polyamide have good ductility during failure, thereby improving the brittle fracture property of the rosin itself.

(5) When the silicone rubber is not added, the specimen exhibits relatively obvious brittle fracture properties. With the increase of the silicone rubber content, the brittle fracture characteristics of the specimen are no longer obvious. The reason may be that the silicone rubber has good ductility, thereby improving the brittle fracture properties of the rosin itself. It can also be seen that as the amount of added silicone rubber increases, the strain corresponding to the maximum stress tends to increase, which may be related to the greater strain of the silicone rubber during failure. In addition, it can be seen that there is no significant difference in the residual strength of the specimen when the amount of added silicone rubber is increased, which may be related to the ductility of the hardened silicone rubber.

\section{Effect of raw materials on elastic modulus of brittle rock-like materials}

Similarly, the relationship between the content of each raw material and the elastic modulus is shown in Fig. 12. It can be seen that in order to increase the elastic modulus of brittle rock-like materials, it can only be achieved by increasing the content of the rosin in the raw materials. When the rosin content increases, the elastic modulus of rock-like materials increases significantly, which may have a great relationship with the elastic modulus of rosin itself.

In the experiment, when the content of sand and barite powder cannot be changed, the purpose of lowering the elastic modulus of the material can be achieved by adding the auxiliary admixture epoxide resin, polyamide, or silicone rubber. It can also be seen from Fig. 12 that silicone rubber has a better effect of lowering the elastic modulus of the material relative to the epoxide resin and the polyamide.

\section{Effect of raw materials on uniaxial compressive strength of brittle rock-like materials}

The uniaxial compressive strength of brittle rock-like material was obtained by the stress-strain curve, and the relationship between the content of each raw material and the uniaxial compressive strength was as shown in Fig. 13.

It can be clearly seen from the figure that the uniaxial compressive strength of the brittle rock-like material can be enhanced by increasing the content of the rosin and adding an appropriate amount of the auxiliary regulator epoxide resin and polyamide. To reduce the uniaxial compressive strength of brittle rock-like materials, the content of sand and barite can be increased, and an appropriate amount of auxiliary regulator silicone rubber can be added.

In the experiment, when the content of sand and barite powder cannot be changed, the purpose of reducing the uniaxial compressive strength of the brittle rock-like material can be achieved by adding the auxiliary admixture silicone rubber. From the effect of the raw material on the stress-strain curve, it can be known that if the uniaxial compressive strength of the brittle rock-like material is to be increased and the brittle rock-like material has a certain ductility, the rosin should not be added too much, but an appropriate amount of the auxiliary regulator epoxide resin and polyamide should be added.

\section{Effect of raw materials on fracture toughness of brittle rock-like materials}

Similarly, the fracture toughness of the brittle rock-like material can also be obtained by substituting the relevant test data into Eqn. 3. The relationship between the fracture toughness and the content of each raw material is shown in Fig. 14. It can be clearly seen that in order to improve the fracture toughness of brittle rock-like materials, it is possible to increase the 
content of rosin and add an appropriate amount of auxiliary regulator epoxide resin and polyamide. It has also been found that the addition of epoxide resin and polyamide to improve the fracture toughness of rock-like materials is better. To reduce the fracture toughness of brittle rock-like materials, the content of sand and barite in the raw materials should be increased, and an appropriate amount of auxiliary regulator silicone rubber can be added.
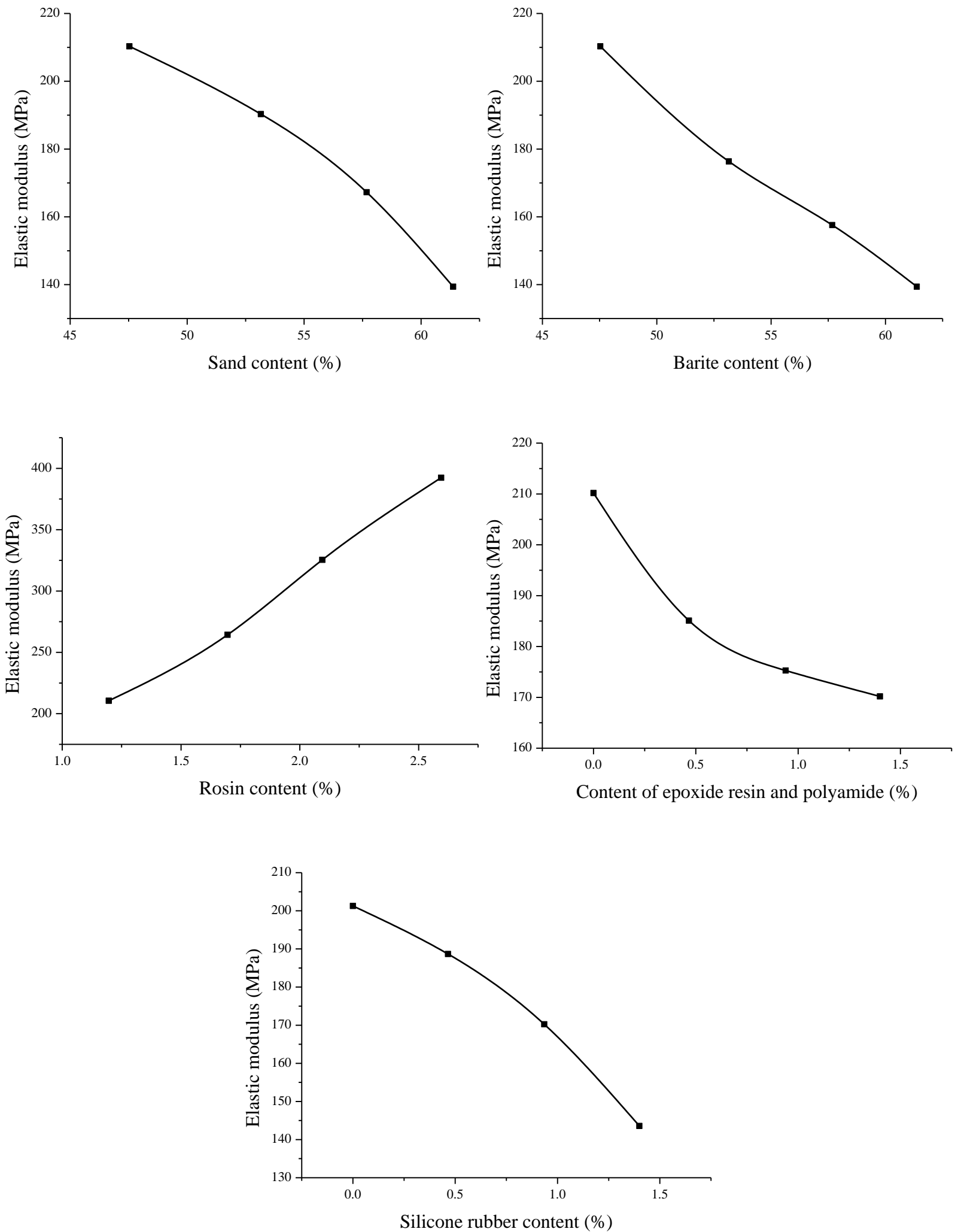

Figure 12: Relationships between raw materials contents and elastic modulus of brittle rock-like materials. 

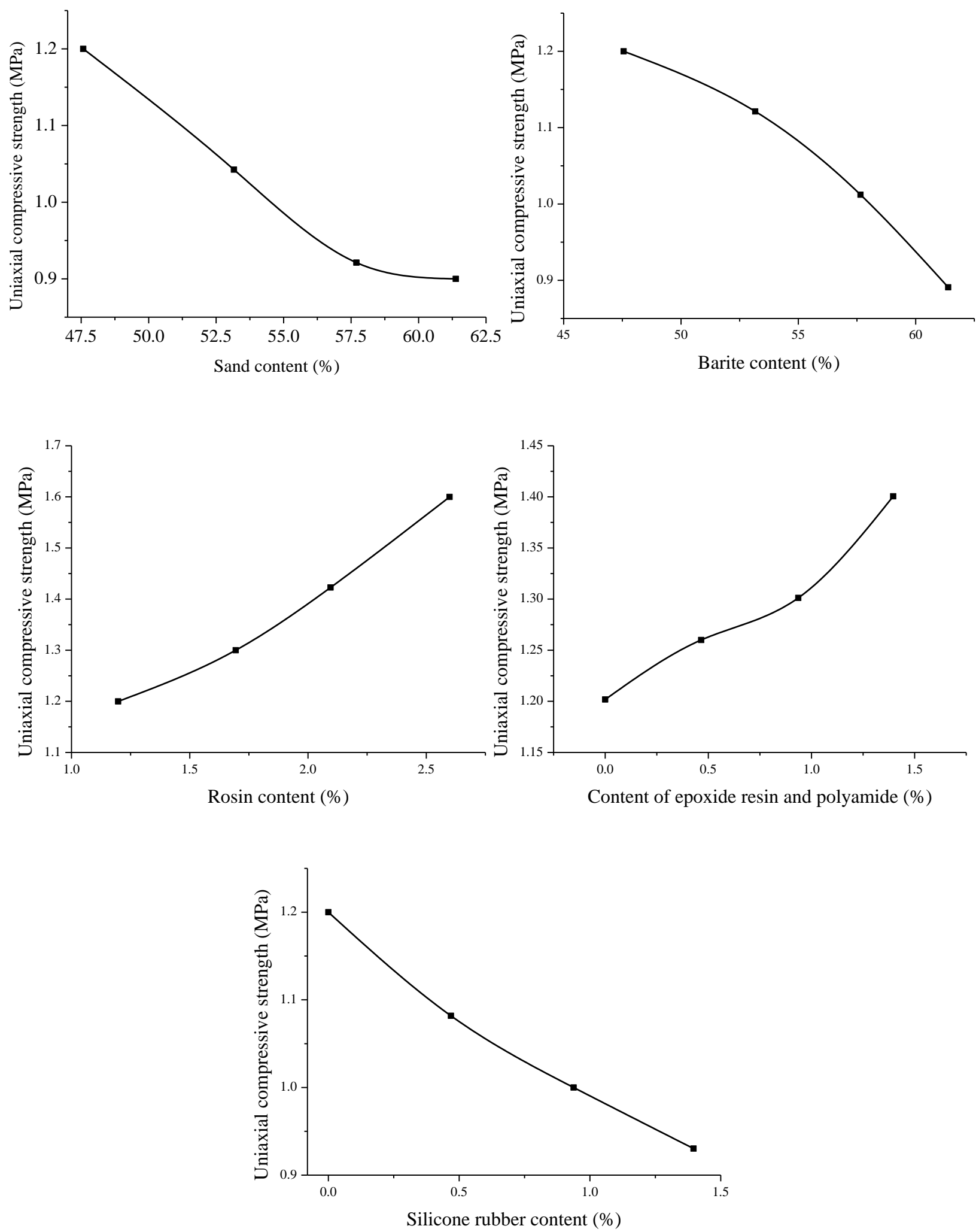

Figure 13: Relationships between raw materials contents and uniaxial compressive strength of brittle rock-like materials. 

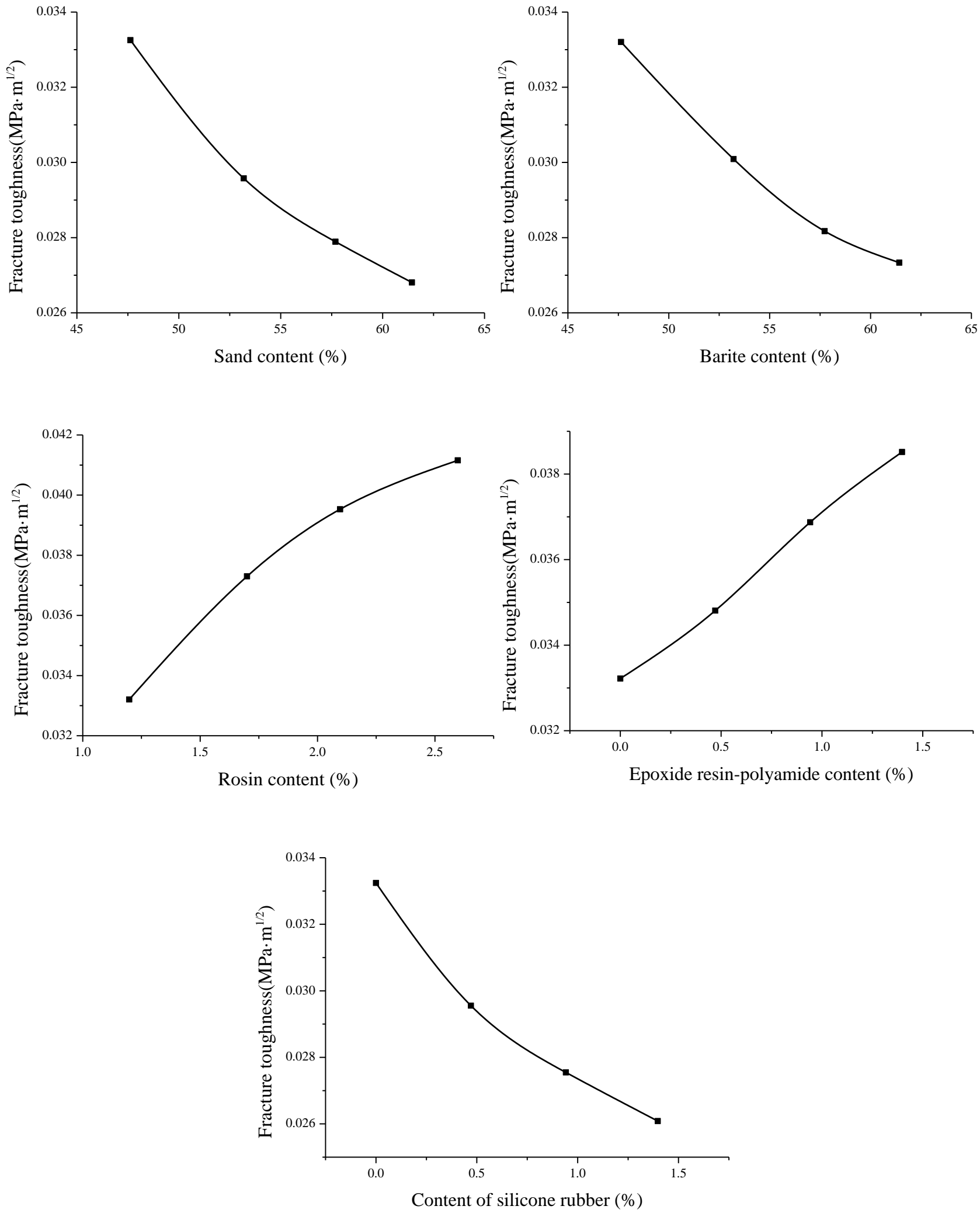

Figure 14: Relationships between raw materials contents and fracture toughness of brittle rock-like materials. 
In the experiment, when the content of sand and barite powder cannot be changed, the purpose of reducing the fracture toughness of the brittle rock-like material can be achieved by adding the auxiliary admixture silicone rubber. From the effect of the raw material on the stress-strain curve, it can be known that if the fracture toughness of the brittle rock-like material is to be increased and the brittle rock-like material has a certain ductility, the rosin should not be added too much, but an appropriate amount of the auxiliary regulator epoxide resin and polyamide should be added.

\section{APPLICATION OF ROCK-LIKE MATERIALS IN CRACK PROPAGATION EXPERIMENTS}

\section{Experimental design}

T $\mathrm{n}$ this experiment, crack propagation studies were carried out on specimens with the same original crack arrangement. According to the previous test results, the raw material ratios of the crack propagation experiment was finally determined, which was divided into the ratio of ductility group and the ratio of brittleness group, as shown in Tab. 3 and Tab. 4.

\begin{tabular}{cccc}
\hline Number & Raw materials & Ratio & Epoxide resin - polyamide content (\%) \\
G1 & Sand, barite, epoxy, polyamide and alcohol & $300: 300: 4: 4: 40$ & 1.23 \\
G2 & Sand, barite, epoxy, polyamide and alcohol & $300: 300: 6: 6: 40$ & 1.84 \\
G3 & Sand, barite, epoxy, polyamide and alcohol & $300: 300: 8: 8: 40$ & 2.47 \\
G4 & Sand, barite, epoxy, polyamide and alcohol & $300: 300: 10: 10: 40$ & 3.11 \\
G5 & Sand, barite, epoxy, polyamide and alcohol & $300: 300: 12: 12: 40$ & 3.61 \\
\hline
\end{tabular}

Table 3: Ductility group ratio.

\begin{tabular}{|c|c|c|c|}
\hline Number & Raw materials & Ratio & Rosin content $(\%)$ \\
\hline $\mathrm{H} 1$ & Sand, barite, rosin and alcohol & $200: 200: 5: 15$ & 1.19 \\
\hline $\mathrm{H} 2$ & Sand, barite, rosin and alcohol & $200: 200: 7: 15$ & 1.66 \\
\hline H3 & Sand, barite, rosin and alcohol & 200:200:9:15 & 2.12 \\
\hline $\mathrm{H} 4$ & Sand, barite, rosin and alcohol & $200: 200: 11: 15$ & 2.58 \\
\hline $\mathrm{H} 5$ & Sand, barite, rosin and alcohol & 200:200:13:15 & 3.04 \\
\hline
\end{tabular}

Table 4: Brittleness group ratio.

The initial crack layout of this experiment is shown in Fig. 15 (2a shows the crack length, c shows the crack unconnected rate, $s$ indicates the crack pitch, and $\alpha$ indicates the crack inclination angle), and the specimen has a pre-crack opening degree of $0.8 \mathrm{~mm}$. The dimension of the specimen are $140 \mathrm{~mm}$ high, $90 \mathrm{~mm}$ wide and $40 \mathrm{~mm}$ thick. In the experiment, the geotechnical experimental servo test machine from Chongqing University was used as the experimental device, which can control the loading mode by using a computer program and collect test data synchronously. Different ways of loading can be performed by setting a computer program, and the loading rate can also be adjusted.

This experiment was to observe the whole process of cracking of cracked specimens, and the crack initiation, expansion and coalescence speed were relatively fast. Therefore, in order to achieve the ideal image acquisition effect, the RDT/16 high-speed dynamic recording system was applied in the experiment. The loading mode of displacement control was selected where the loading rate was $1 \mathrm{~mm} / \mathrm{min}$, and the shooting speed of the high-speed dynamic recording system during loading was 25 images per second. 


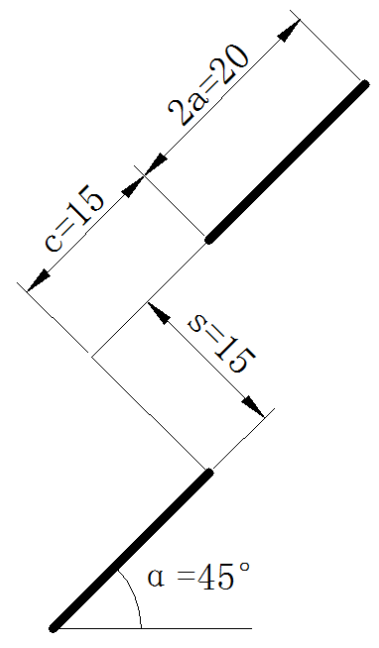

Figure 15: Crack layout.

\section{Characteristics of the crack propagation process}

Comparative analysis of crack initiation modes

Tab. 5 is a comparison table of the crack initiation modes of the ductile group. The content of epoxide resin and polyamide is gradually reduced from left to right, that is, the brittleness of the material is gradually increased.

By comparing and analyzing Tab. 5, it can be seen that as the content of epoxide resin and polyamide decreases gradually, the new crack initiation mode gradually changes from the state where the initial wing crack and shear crack coexist to only the wing crack. Through the observation of the experimental loading process and the analysis of the experimental data, it is found that there is no significant difference in the vertical compression displacement of each specimen when the new crack starts to sprout.

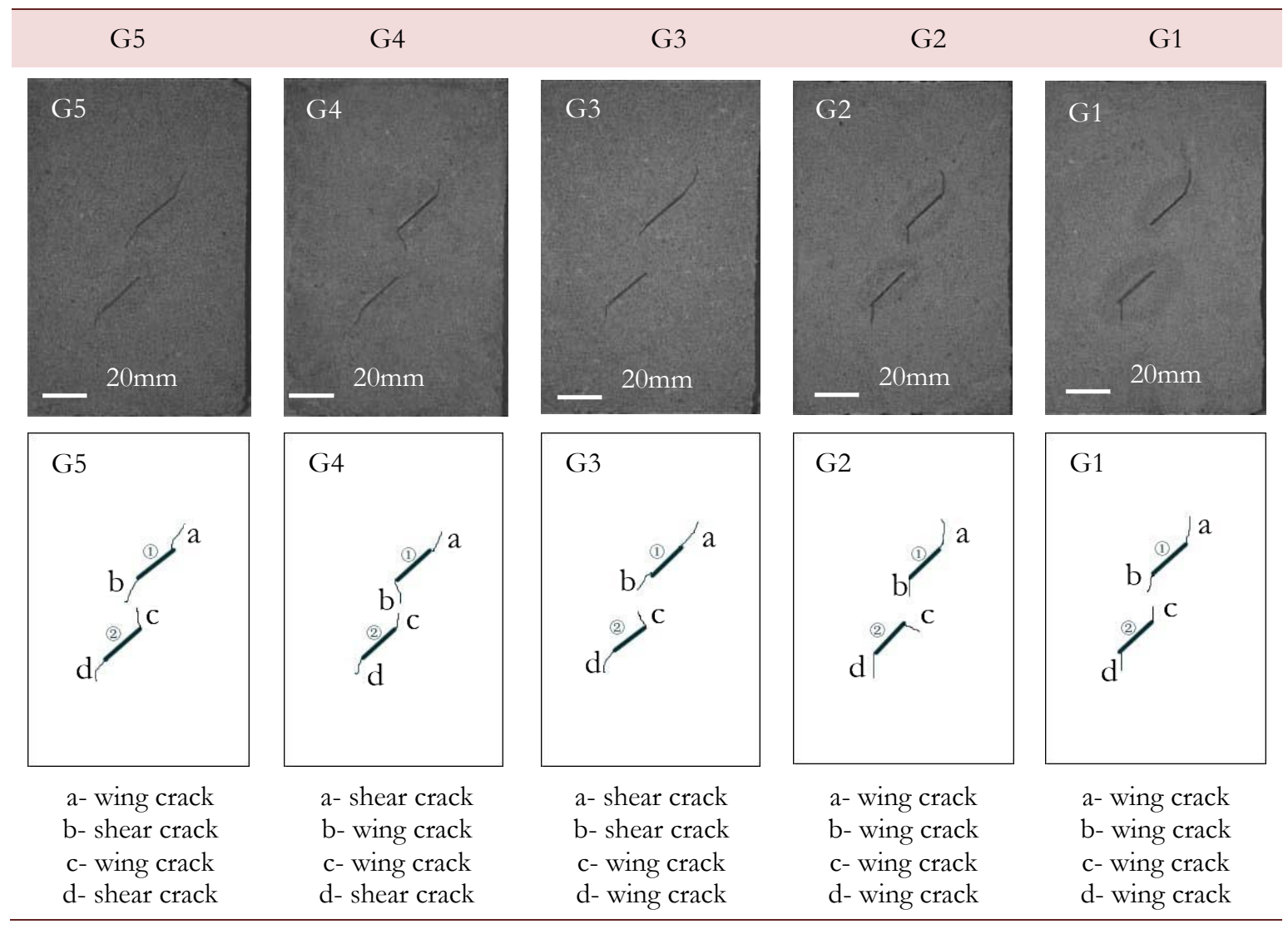

Table 5: Crack initiation mode of the ductile group. 
Tab. 6 is a comparison table of the crack initiation modes of the brittle group. The rosin content increases from left to right, that is, the brittleness of the material increases gradually.

By comparing and analyzing Tab. 6, it can be seen that as the rosin content increases gradually, the new crack initiation mode is almost all wing crack. Observing the experimental loading process and analyzing the experimental data, it is found that when the new crack begins to sprout, the vertical compression displacement of the specimen with more rosin content is smaller.

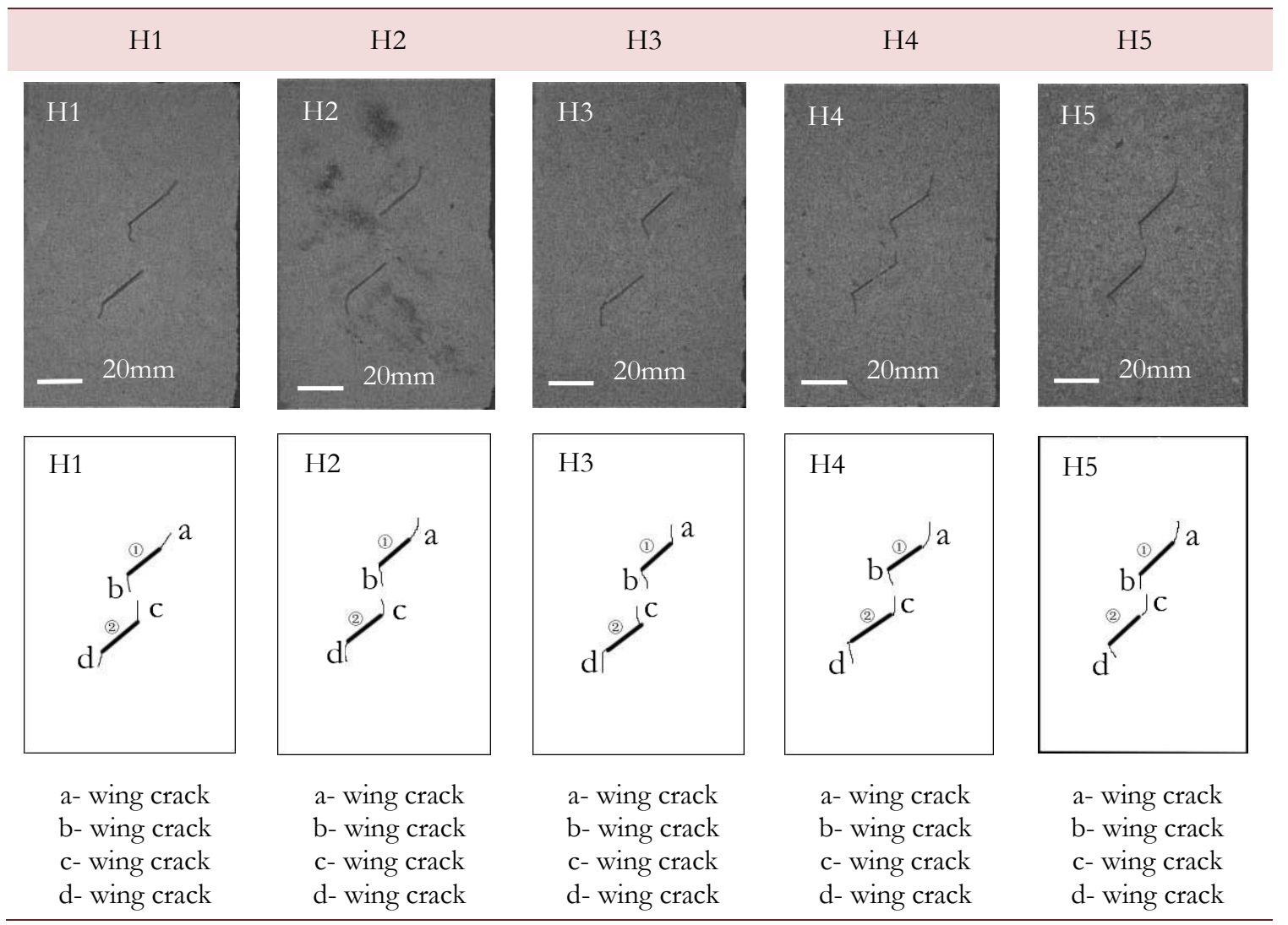

Table 6: Crack initiation mode of the brittle group.

According to the comprehensive analysis of the two tables, as the brittleness of the material increases gradually, the new crack initiation mode of the rock-like material gradually changes from shear crack to wing crack. At the same time, when the new crack starts to sprout, the vertical compression displacement of the specimen gradually decreases.

\section{Comparative analysis of crack coalescence failure mode}

Tab. 7 is a comparison table of the crack coalescence failure modes of the ductile group. The content of epoxide resin and polyamide gradually reduces from left to right, that is, the brittleness of the material gradually increases.

By comparing and analyzing Tab. 7, it can be seen that as the content of epoxide resin and polyamide reduces gradually, the crack coalescence failure mode gradually changes from the initial composite failure of tensile and shear to the tensile failure. Observing the experimental loading process and analyzing the experimental data, it can be found that when the cracks coalesce, the vertical compression displacement of the specimen with lower content of epoxide resin and polyamide is smaller.

Tab. 8 is a comparison table of the crack coalescence failure modes of brittle group. The content of rosin is gradually increased from left to right, that is, the brittleness of the material is gradually increased.

By comparing and analyzing Tab. 8, it can be seen that as the content of rosin increases gradually, the crack coalescence failure mode is almost all tensile failure. Observing the experimental loading process and analyzing the experimental data, it can be found that when the cracks coalesce, the vertical compression displacement of the specimen with more rosin content is smaller.

According to the comprehensive analysis of the two tables, as the brittleness of the material increases gradually, the crack coalescence failure mode of the rock-like material gradually changes from the composite failure of tensile and shear to tensile 
failure. At the same time, the vertical compression displacement of the specimen gradually decreases when the cracks coalesce.

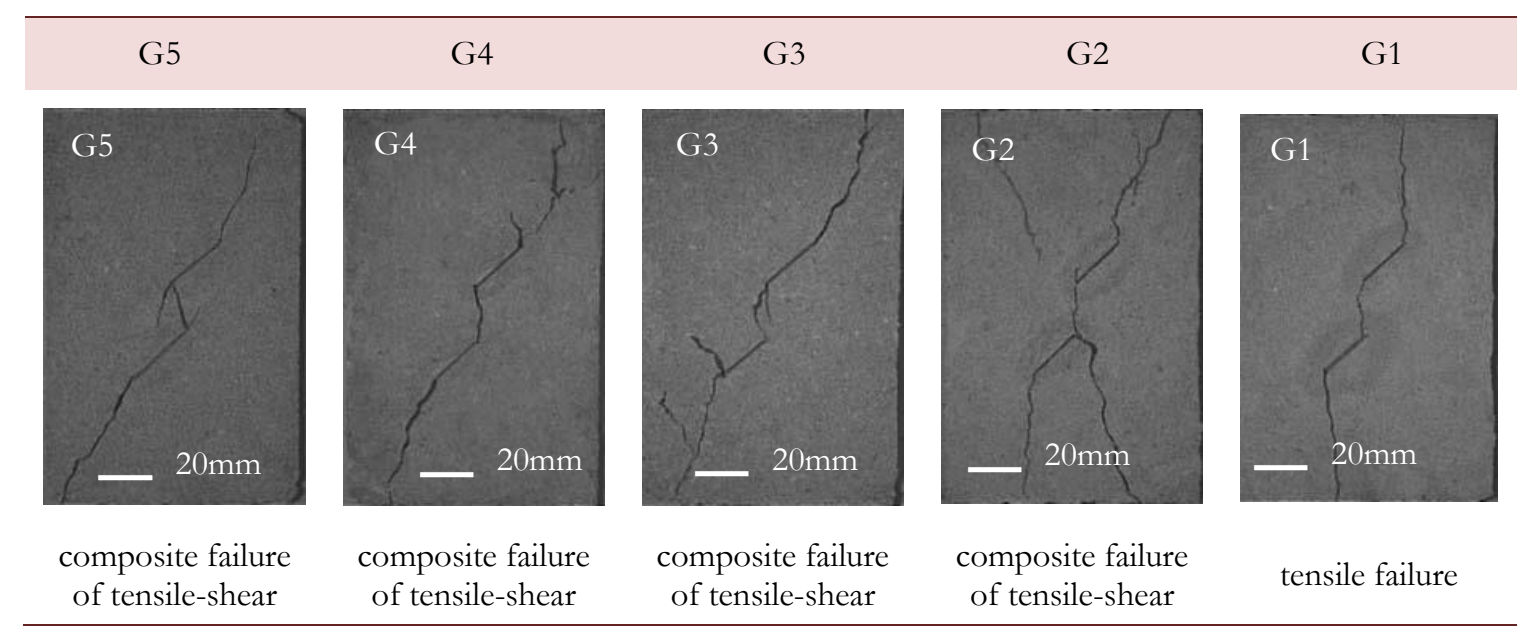

Table 7: Sketch of crack coalescence of ductile group.

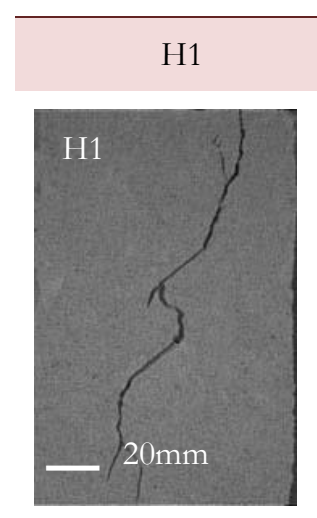

Tensile failure
$\mathrm{H} 2$

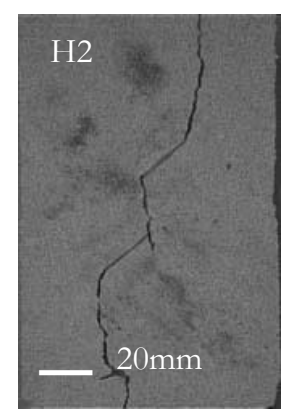

Tensile failure
H3

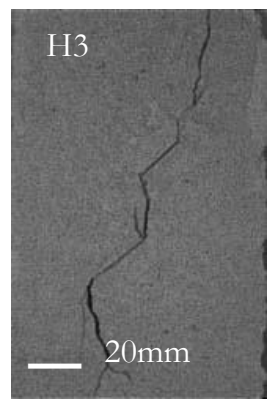

Tensile failure
$\mathrm{H} 4$

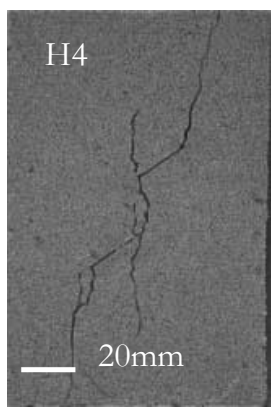

Tensile failure
H5

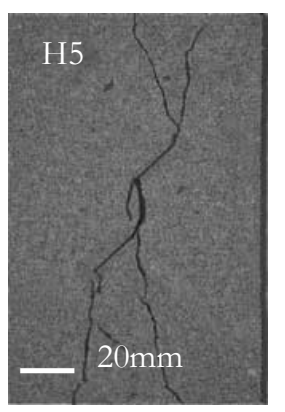

Tensile failure

Table 8: Sketch of crack coalescence.

\section{Analysis of mechanical properties of rock-like materials \\ Analysis of crack initiation stress \\ (1) Crack initiation stress of ductile group}

Crack initiation stress refers to the value of instantaneous stress when the initial crack of the specimen is expanded to form a new crack. Under the action of uniaxial compression load, the two initial pre-cracks in the specimen do not necessarily produce new cracks at the same time, that is, the initial crack initiation stress of the two initial pre-cracks may be different. Comparing the photos taken by the high-speed camera at different times with the stresses and strains recorded by the uniaxial compression servo system, then the time, strain and stress of cracking of each initial pre-crack can be determined. The crack initiation stress and its average value of the two initial pre-cracks are shown in Tab. 9 and Tab. 10. The relationship between the crack initiation stress and the ratio of different raw materials is shown in Fig. 16.

It is found that each specimen produces new cracks in the experiment. Moreover, it can be found that changing the content of epoxide resin-polyamide or rosin, the crack initiation stress of the first crack in the specimen is not significantly different from the crack initiation stress of the second crack. The reason may be that the cracking of the first crack causes stress redistribution, which in turn causes rapid cracking of the other crack. By comparing and analyzing the crack initiation stress of the specimen with different content of epoxide resin-polyamide or rosin, it is found that the initial pre-crack in the specimen with less content of epoxide resin-polyamide or rosin is more susceptible to cracking. 


\begin{tabular}{cccc}
\hline Number & $\begin{array}{r}\text { Crack initiation stress of } \\
\text { crack(1) }\end{array}$ & $\begin{array}{c}\text { Crack initiation stress of } \\
\text { crack(2) }\end{array}$ & $\begin{array}{c}\text { Average value of crack } \\
\text { initiation stress }\end{array}$ \\
G1 & 0.61 & 0.71 & 0.66 \\
G2 & 0.78 & 0.72 & 0.75 \\
G3 & 0.82 & 0.94 & 0.88 \\
G4 & 1.07 & 1.11 & 1.09 \\
G5 & 1.38 & 1.34 & 1.36 \\
\hline
\end{tabular}

Table 9: Crack initiation stress of ductile group (MPa).

\begin{tabular}{cccc}
\hline Number & $\begin{array}{r}\text { Crack initiation stress of } \\
\text { crack(1) }\end{array}$ & $\begin{array}{c}\text { Crack initiation stress of } \\
\text { crack2 }\end{array}$ & $\begin{array}{c}\text { Average value of crack } \\
\text { initiation stress }\end{array}$ \\
H1 & 0.63 & 0.55 & 0.59 \\
H2 & 0.86 & 0.76 & 0.81 \\
H3 & 0.93 & 0.97 & 0.95 \\
H4 & 1.11 & 1.13 & 1.12 \\
H5 & 1.19 & 1.15 & 1.17 \\
\hline
\end{tabular}

Table 10: Crack initiation stress of brittle group (MPa).
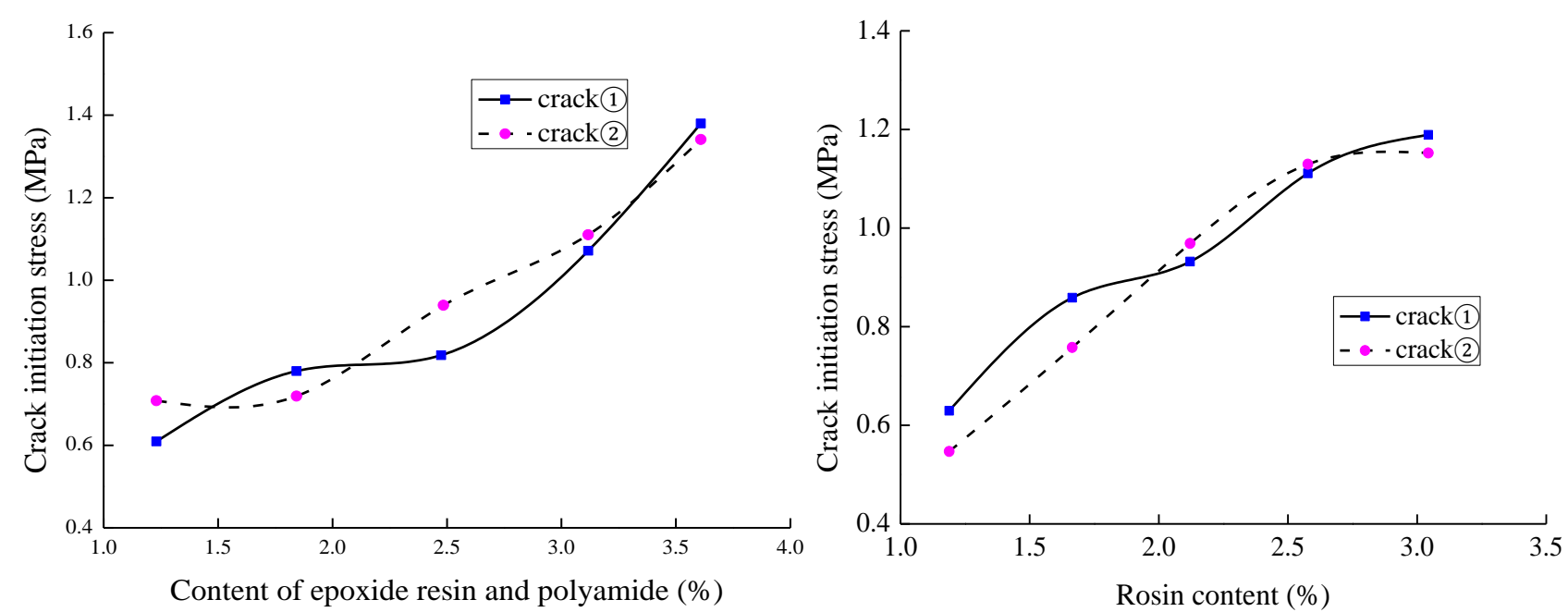

Figure 16: The crack initiation stress of two cracks in specimens.

\section{Analysis of peak strain}

(1) Peak strain of ductile group

The peak strain of the specimen with different epoxide resin-polyamide content was obtained by processing the experiment data, as shown in Tab. 11. The relationship between the peak strain of the specimen and the content of epoxide resinpolyamide is shown in Fig. 17.

It can be seen from the figure that the minimum peak strain of the specimen is $0.80 \%$ and the maximum peak strain is $1.55 \%$. Therefore, it can be considered that the change of the content of epoxide resin-polyamide has a relatively striking influence on the peak strain of the specimen. At the same time, with the increase of epoxide resin-polyamide content, the 
peak strain of the specimen shows an increasing trend. Meanwhile the peak strain increases rapidly from the beginning, and then increases slowly.

\begin{tabular}{cccccc}
\hline Epoxide resin - polyamide content (\%) & 1.23 & 1.84 & 2.47 & 3.11 & 3.61 \\
Peak strain (\%) & 0.80 & 1.04 & 1.23 & 1.47 & 1.55 \\
\hline
\end{tabular}

Table 11: Peak strain of ductile group.

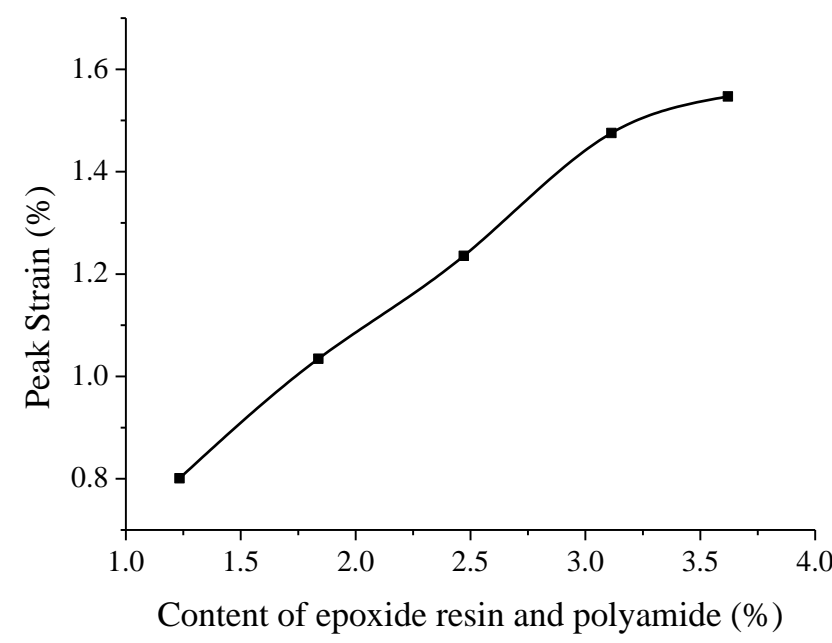

Figure 17: The relationship between peak strain and epoxide resin-polyamide content.

(2) Peak strain of brittle group

The peak strain of the specimen with different rosin content was obtained by processing the experiment data, as shown in Tab. 12. The relationship between the peak strain of the specimen and the rosin content is shown in Fig. 18.

It can be seen from the figure that the minimum peak strain of the specimen is $0.41 \%$ and the maximum peak strain is $0.70 \%$. Therefore, it can be considered that the change of the rosin content has modest influence on the peak strain of the specimen but is not very obvious. At the same time, with the rosin content increases, the peak strain of the specimen shows a decreasing trend, and the strain decreases rapidly from the start and then decreases slowly.

\begin{tabular}{cccccc}
\hline Rosin content (\%) & 1.19 & 1.65 & 2.13 & 2.56 & 3.05 \\
Peak strain (\%) & 0.70 & 0.64 & 0.51 & 0.44 & 0.41 \\
\hline
\end{tabular}

Table 12: Peak strain of brittle group.

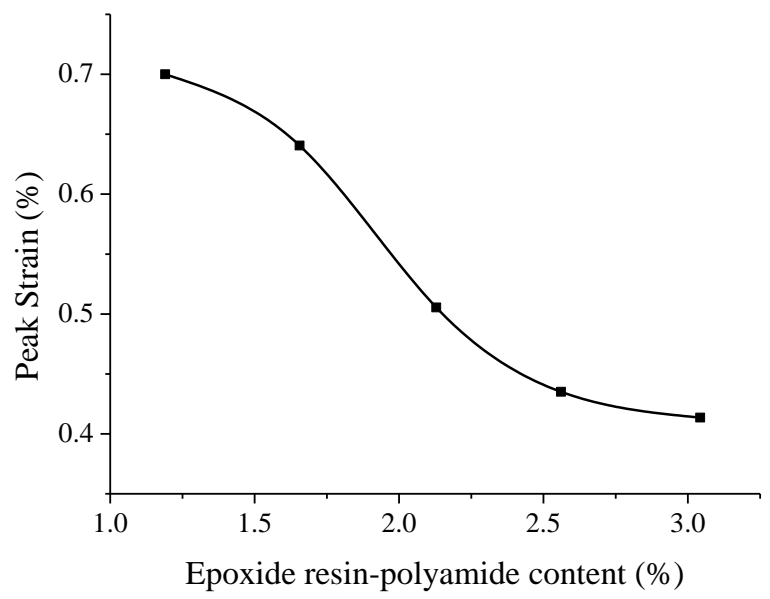

Figure 18: The relationship between peak strain and rosin content. 
By comparing the peak strains of the ductile group and the brittle group, it can be known that the content of the cementitious material has a certain influence on the peak strain of the material. Moreover, with the brittleness of the material increases, the peak strain of the material gradually decreases.

\section{Analysis of crack connection mode and connection stress}

Tab. 13 is a table of crack connection modes of ductile group. The epoxide resin-polyamide content gradually reduces from left to right, that is, the brittleness of the material gradually increases. By analyzing Tab. 13, it shows that as the epoxide resin-polyamide content decreases gradually, the crack connection mode has no obvious regularity, and the wing crack connection is the main connection mode. At the same time, it can be found that as the epoxide resin-polyamide content reduces, and correspondingly the crack connection stress gradually reduces.

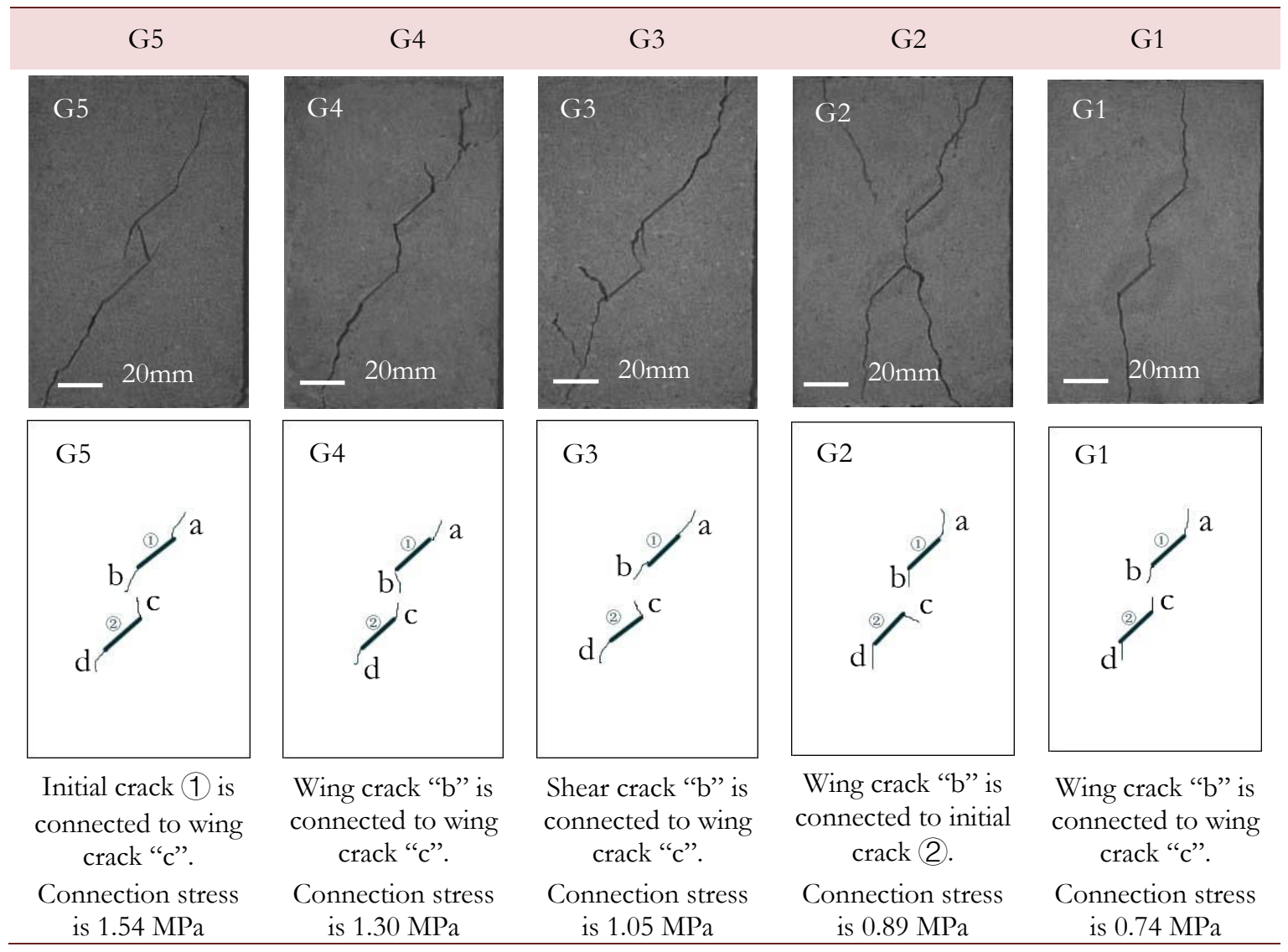

Table 13: Crack connection mode of ductile group.

Tab. 14 is a table of crack connection modes of brittle group. The rosin content gradually increases from left to right, that is, the brittleness of the material gradually increases. Through the analysis of Tab. 14, it indicates that as the rosin content increases gradually, the crack connection mode has no obvious regularity, and the wing crack connection is the main connection mode. At the same time, it can be found that as the rosin content increases, the crack connection stress gradually increases accordingly.

In order to compare the relative magnitude relationship between crack initiation stress, connection stress and peak intensity, a comparative analysis of the three is performed, as shown in Fig. 19. It can be found that as the epoxide resin-polyamide content increases gradually, that is, the ductility of the material gradually increases, the crack connection stress gradually approaches the peak strength. At the same time, as the rosin content increases gradually, that is, the brittleness of the material increases gradually, the crack connection stress gradually approaches the initiation stress.

Future developments will be addressed to improve the mechanical strength in case of more complex geometrical discontinuities [38-39]. A specific focus on the cyclic behavior will be addressed to improve the total final fatigue life at room [40-42] and high temperature [43] as made for traditional materials. This will allow to improve locally the strength to counterbalance local geometrical effects that can occur in a real 3D component [44-49]. 

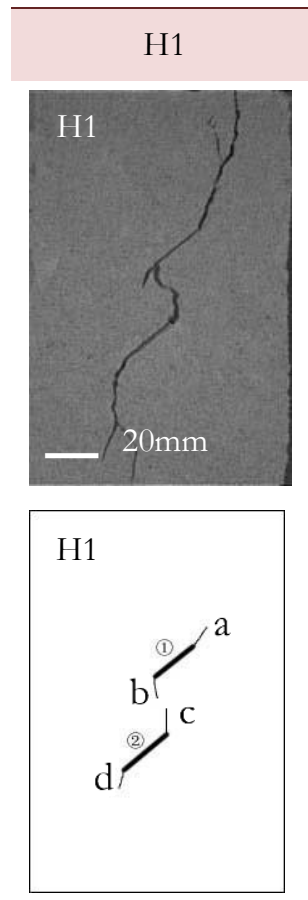

Wing crack " $b$ " is connected to wing crack "c".

Connection stress is $0.73 \mathrm{MPa}$
$\mathrm{H} 2$
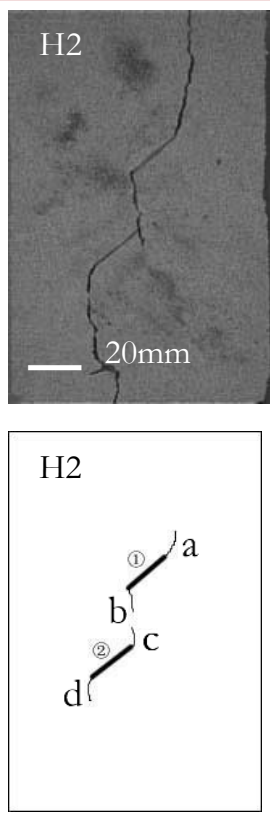

Wing crack " $\mathrm{b}$ " is connected to wing crack "c".

Connection stress is $0.90 \mathrm{MPa}$
H3
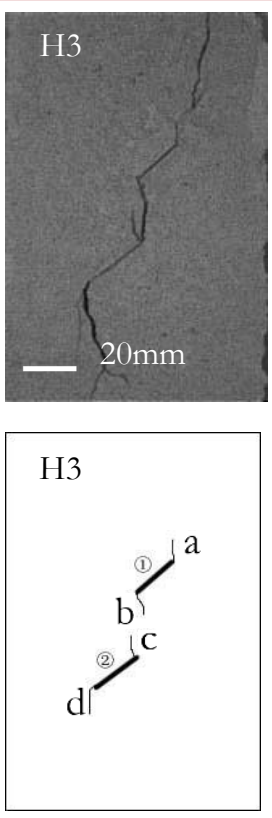

Wing crack " $b$ " is connected to initial crack (2).

Connection stress is $1.06 \mathrm{MPa}$
H4
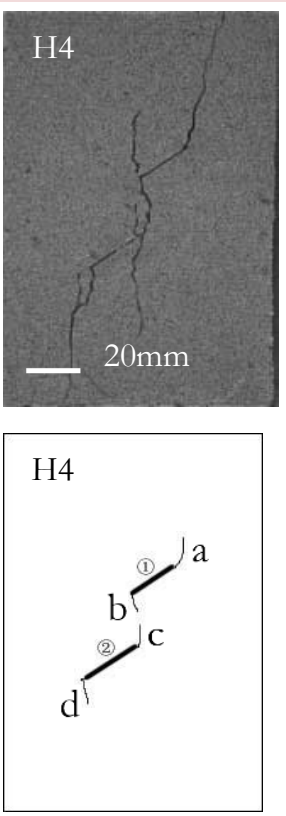

Wing crack " $b$ " is connected to wing crack "c".

Connection stress is $1.17 \mathrm{MPa}$
H5

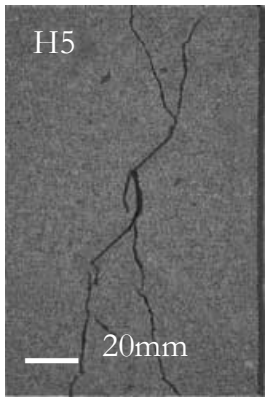

H5

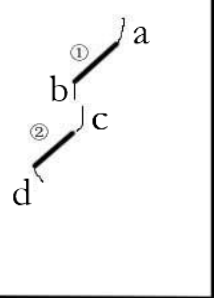

Wing crack "b" is connected to wing crack "c".

Connection stress is $1.22 \mathrm{MPa}$

Table 14: Crack connection mode of brittle group.
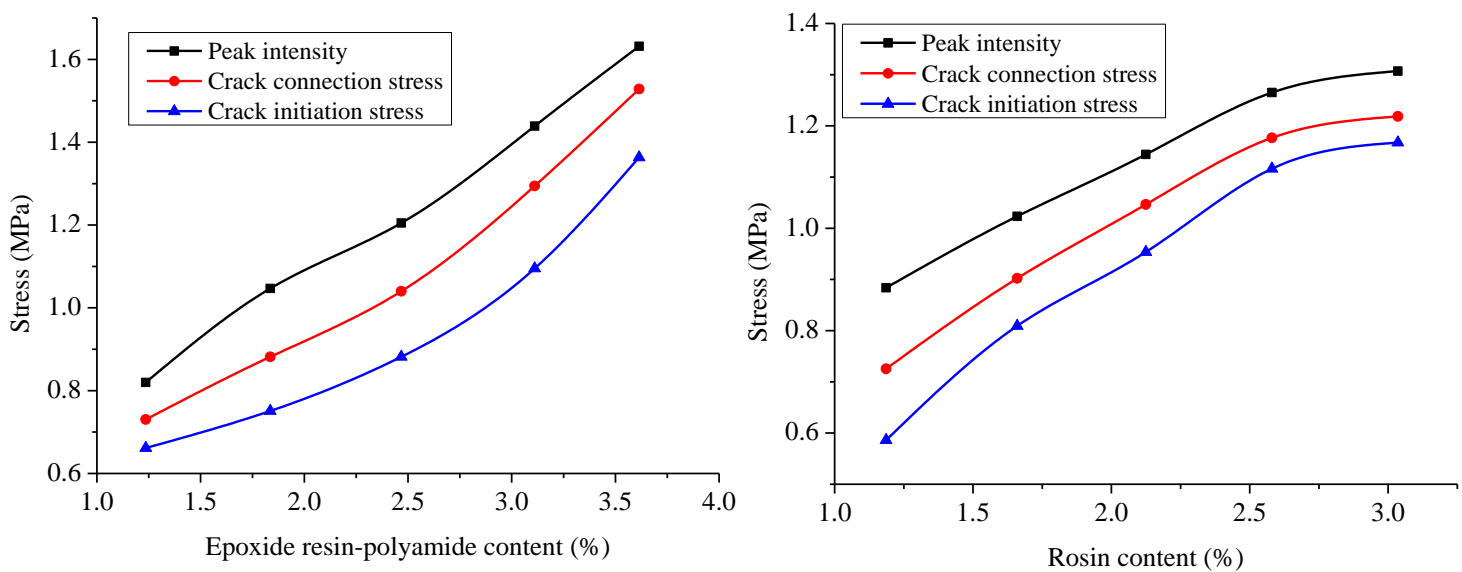

Figure 19: The relationship between peak intensity, connection stress and initiation stress.

\section{CONCLUSIONS}

B

ased on the mechanical properties of ductile and brittle rocks, certain raw materials were selected and the mechanical laws of ductile and brittle rock-like materials were obtained. And two rock-like materials were applied to the experiment of crack propagation. The main conclusions can be summarized as follows:

For the simulation of ductile rock-like materials, sand and barite powder as filler materials, epoxide resin and polyamide as cementitious materials, and alcohol as organic solvent can be chosen. When the content of the cementitious material increases, the uniaxial compressive strength and fracture toughness of the ductile rock-like material significantly improve, 
and the change of elastic modulus is not obvious. When the content of other raw materials cannot be changed, the addition of auxiliary material silicone rubber is mainly to reduce the elastic modulus and strength of this ductile rock-like material, and the addition of rosin is mainly to improve the elastic modulus and brittleness of ductile rock-like materials. Similarly, using sand and barite powder as a filling material, rosin as a cementitious material, and alcohol as an organic solvent brittle rock-like materials can be better simulated. When the content of the cementitious material increases, the elastic modulus and the uniaxial compressive strength of brittle rock-like materials significantly improve, and the fracture toughness even improves more obviously. When the content of other raw materials cannot be changed, the auxiliary materials epoxide resin and polyamide are mainly added to make the brittle rock-like materials have certain ductility, and the addition of silicone rubber is mainly to reduce the elastic modulus and brittleness of brittle rock-like materials.

Through the crack propagation model experiment of rock-like materials, it is found that as the brittleness of the material increases, the new crack initiation mode of the rock-like material gradually changes from shear crack to wing crack, and the vertical compression displacement of the specimen will gradually decrease when the new crack starts to sprout. When the cracks coalesce, the wing crack connection is the main connection mode, and the vertical compression displacement of the specimen with low content of epoxide resin and polyamide in the ductile group or high content of rosin in the brittle group is smaller. It can be also known that the damage of the ductile group specimen is mainly based on the tensile-shear composite failure mode, while the damage of the brittle group specimen is mostly the tensile failure mode. Moreover, for the specimens of ductile group, as the content of epoxide resin and polyamide increases gradually, the crack connection stress increases and gradually approaches the peak strength. For the specimens of brittle group, as the rosin content increases gradually, the crack connection stress increases but gradually approaches the initiation stress.

\section{ACKNOWLEDGEMENTS}

he work is supported by the National Natural Science Foundation of China (Nos. 41807251, 52027814, 51809198, 51839009 and 51679017), Fundamental Research Funds for the Central Universities (No. 2042018kf0008).

\section{REFERENCES}

[1] Brace, W.F. and Bombolakis, E.G. (1963). A note on brittle crack growth in compression, J. Geophys. Res., 68(12), pp. 3709-3713. DOI: 10.1029/JZ068i012p03709.

[2] Hoek, E. and Bieniawski, Z.T. (1965). Brittle fracture propagation in rock under compression, Int. J. Fract., 1(3), pp. 137-155. DOI: 10.1007/BF00186851.

[3] Bieniawski, Z.T. (1967). Mechanism of brittle fracture of rock, part II—experimental studies, Int. J. Rock Mech. Min. Sci., 4(4), pp. 407-423. DOI: 10.1016/0148-9062(67)90031-9.

[4] Horii, H. and Nemat-Nasser, S. (1985). Compression-induced microcrack growth in brittle solids: axial splitting and shear failure, J. Geophys. Res., 90(B4), pp. 3105-3125. DOI: 10.1029/JB090iB04p03105.

[5] Petit, J. and Barquins, M. (1988). Can natural faults propagate under mode II conditions, Tectonics, 7(6), pp. 12431256. DOI: $10.1029 /$ TC007i006p01243.

[6] Chaker, C. and Barquins, M. (2015). Sliding effect on branch crack, Phys. Chem. Earth, 21(4), pp. 319-323. DOI: 10.1016/S0079-1946(97)00055-4.

[7] Cao, P., Liu, T., Pu, C. and Lin, H. (2015). Crack propagation and coalescence of brittle rock-like specimens with preexisting cracks in compression, Eng. Geol., 187, pp. 113-121. DOI: 10.1016/j.enggeo.2014.12.010.

[8] Wong, R.H.C. and Chau, K.T. (1998). Crack coalescence in a rock-like material containing two cracks, Int. J. Rock Mech. Min. Sci., 35(2), pp. 147-164. DOI: 10.1016/S0148-9062(97)00303-3.

[9] Wong, R.H.C., Chau, K.T., Tang, C.A. and Lin, P. (2001). Analysis of crack coalescence in rock-like materials containing three flaws_-part I: experimental approach, Int. J. Rock Mech. Min. Sci., 38(7), pp. 909-924.

DOI: $10.1016 /$ S1365-1609(01)00064-8.

[10] Zhou, X.P., Cheng, H. and Feng, Y.F. (2014). An experimental study of crack coalescence behaviour in rock-like materials containing multiple flaws under uniaxial compression, Rock Mechanics Rock Engineering, 47, pp. 1961-1986. DOI: $10.1007 / \mathrm{s} 00603-013-0511-7$.

[11] Cheng, H., Zhou, X.P., Zhu, J. and Qian, Q.H. (2016). The effects of crack openings on crack initiation, propagation and coalescence behavior in rock-like materials under uniaxial compression, Rock Mechanics Rock Engineering, 49, pp. 3481-3494. DOI: 10.1007/s00603-016-0998-9. 
[12] Reyes, O. and Einstein, H.H. (1991). Failure mechanisms of fractured rock: A fracture coalescence model, Proc. seventh Int. Congr. Rock Mech., 1, pp. 333-340.

[13] Shen, B., Stephansson, O., Einstein, H.H. and Ghahreman, B. (1995). Coalescence of fractures under shear stress experiments, J. Geophys. Res. 100(B4), pp. 5975-5990. DOI: 10.1029/95JB00040.

[14] Bobet, A. and Einstein, H.H. (1998). Fracture coalescence in rock-type materials under uniaxial and biaxial compression, Int. J. Rock Mech. Min. Sci., 35(7), pp. 863-888. DOI: 10.1016/S0148-9062(98)00005-9.

[15] Sagong, M. and Bobet, A. (2002). Coalescence of multiple flaws in a rock-model material in uniaxial compression, Int. J. Rock Mech. Min. Sci., 39(2), pp. 229-241. DOI: 10.1016/S1365-1609(02)00027-8.

[16] Wong, L.N.Y. and Einstein, H.H. (2006). Fracturing behavior of prismatic specimens containing single flaws, Proceedings of the 41 st US symposium on rock mechanics, June. Colorado. USA.

[17] Wong, L.N.Y. and Einstein, H.H. (2009). Crack coalescence in molded gypsum and Carrara marble: part 1. Macroscopic observations and interpretation, Rock Mech. Rock Eng., 42, pp. 475-511. DOI: 10.1007/s00603-008-0003-3.

[18] Wong, L.N.Y. and Einstein, H.H. (2009). Crack coalescence in molded gypsum and Carrara marble: part 2. Microscopic observations and interpretation, Rock Mech. Rock Eng., 42, pp. 513-545. DOI: 10.1007/s00603-008-0002-4.

[19] Basu, A., Mishra, D.A. and Roychowdhury, K. (2013). Rock failure modes under uniaxial compression, Brazilian, and point load tests, Bull. Eng. Geol. Environ., 72, pp. 457-475. DOI: 10.1007/s10064-013-0505-4.

[20] Liang, C.Y. Zhang, Q.B., Li, X. and Xin, P. (2016). The effect of specimen shape and strain rate on uniaxial compressive behavior of rock material, Bull. Eng. Geol. Environ., 75, pp. 1669-1681. DOI: 10.1007/s10064-015-0811-0.

[21] Zhao, F. and He, M.C. (2017). Size effects on granite behavior under unloading rockburst test, Bull. Eng. Geol. Environ., 76, pp. 1183-1197. DOI: 10.1007/s10064-016-0903-5.

[22] Zou, C. and Wong, L.N.Y. (2014). Experimental studies on cracking processes and failure in marble under dynamic loading, Eng. Geol., 173, pp. 19-31. DOI: 10.1016/j.enggeo.2014.02.003.

[23] Hu, M., Liu, Y.X., Ren, J.B., Wu, R. and Zhang, Y. (2019). Laboratory test on crack development in mudstone under the action of dry-wet cycles, Bull. Eng. Geol. Environ., 78, pp. 543-556. DOI: 10.1007/s10064-017-1080-x.

[24]Zhou, X.P., Bi, J. and Qian, Q.H. (2015). Numerical Simulation of Crack Growth and Coalescence in Rock-Like Materials Containing Multiple Pre-existing Flaws, Rock Mechanics and Rock Engineering, 48(3), pp. 1097-1114.

DOI: $10.1007 / \mathrm{s} 00603-014-0627-4$.

[25] Bi, J., Zhou, X.P. and Qian, Q.H. (2016). The 3D Numerical Simulation for the Propagation Process of Multiple Preexisting Flaws in Rock-Like Materials Subjected to Biaxial Compressive Loads, Rock Mechanics and Rock Engineering, 49(5), pp. 1611-1627. DOI: 10.1007/s00603-015-0867-y.

[26] Wang, Y.T., Zhou, X.P., Wang, Y. and Shou, Y.D. (2018). A 3-D conjugated bond-pair-based peridynamic formulation for initiation and propagation of cracks in brittle solids, International Journal of Solids and Structures, 134, pp. 89-115. DOI: $10.1016 /$ j.ijsolstr.2017.10.022.

[27] Wang, Y.T., Zhou, X.P. and Shou, Y.D. (2017). The modeling of crack propagation and coalescence in rocks under uniaxial compression using the novel conjugated bond-based peridynamics, International Journal of Mechanical Sciences, 128, pp. 614-643. DOI: 10.1016/j.ijmecsci.2017.05.019.

[28] Zhou, X.P. and Yang, H.Q. (2008). Micromechanical modeling of dynamic compressive responses of mesoscopic heterogenous brittle rock, Theoretical and Applied Fracture Mechanics, 48(1), pp. 1-20.

DOI: $10.1016 /$ j.tafmec.2007.04.008.

[29]Zhou, X.P., Zhang, Y.X., Ha, Q.L. and Zhu, K.S. (2008). Micromechanical Modelling of the Complete Stress-Strain Relationship for Crack Weakened Rock Subjected to Compressive Loading, Rock Mechanics and Rock Engineering, 41(5), pp. 747-769. DOI: 10.1007/s00603-007-0130-2.

[30] Zhou, X.P., Zhang, J.Z. and Wong, L.N.Y. (2018). Experimental Study on the Growth, Coalescence and Wrapping Behaviors of 3D Cross-Embedded Flaws Under Uniaxial Compression, Rock Mechanics and Rock Engineering, 51(5), pp. 1379-1400. DOI:10.1007/s00603-018-1406-4.

[31] Zhou, X.P., Zhang, J.Z. Qian, Q.H. and Niu, Y. (2019). Experimental investigation of progressive cracking processes in granite under uniaxial loading using digital imaging and AE techniques, Journal of Structural Geology, 126, pp. 129145. DOI: $10.1016 /$ j.jsg.2019.06.003.

[32] Zhang, J.Z., Zhou, X.P., Zhou, L.S. and Berto, F. (2019). Progressive failure of brittle rocks with non-isometric flaws: Insights from acousto-optic-mechanical (AOM) data, Fatigue \& Fracture of Engineering Materials \& Structures, 42(8), pp. 1787-1802. DOI: $10.1111 /$ ffe.13019.

[33] Zhang, J.Z. and Zhou, X.P. (2020). Forecasting Catastrophic Rupture in Brittle Rocks Using Precursory AE Time Series, Journal of Geophysical Research-Solid Earth, 125(8), e2019JB019276. DOI: 10.1029/2019JB019276. 
[34] Zhang, J.Z. and Zhou. X.P. (2020). AE event rate characteristics of flawed granite: from damage stress to ultimate failure, Geophysical Journal International, 222(2), pp. 795-814. DOI: 10.1093/gji/ggaa207.

[35] Zhou, X.P., Wang, Y.T., Zhang, J.Z. and Liu. F.N. (2019). Fracturing Behavior Study of Three-Flawed Specimens by Uniaxial Compression and 3D Digital Image Correlation: Sensitivity to Brittleness, Rock Mechanics and Rock Engineering, 52(3), pp. 691-718. DOI: 10.1007/s00603-018-1600-4.

[36] Zhou, X.P., Lian, Y.J., Wong, L.N.Y. and Berto, F. (2018). Understanding the fracture behavior of brittle and ductile multi-flawed rocks by uniaxial loading by digital image correlation, Engineering Fracture Mechanics, 199, pp. 438-460. DOI: 10.1016/j.engfracmech.2018.06.007.

[37] Kjellman, W. (1936). Report on an apparatus for con-summate investigation of the mechanical properties of soils, Proceedings of the 1st ICSMFE, pp. 16-20.

[38] Ayatollahi, M.R., Rashidi Moghaddam, M., Razavi, S.M.J., Berto, F. (2016). Geometry effects on fracture trajectory of PMMA samples under pure mode-I loading, Engineering Fracture Mechanics, 163, pp. 449-461.

DOI: $10.1016 /$ j.engfracmech.2016.05.014.

[39] Torabi, A.R., Campagnolo, A., Berto, F. (2015). Local strain energy density to predict mode II brittle fracture in Brazilian disk specimens weakened by V-notches with end holes Materials and Design, 69, pp. 22-29. DOI: $10.1016 /$ j.matdes.2014.12.037.

[40] Zhu, S-P., Yu, Z-Y, Correia, J., De Jesus, A., Berto, F. (2018). Evaluation and comparison of critical plane criteria for multiaxial fatigue analysis of ductile and brittle materials, International Journal of Fatigue, 112, pp. 279-288, DOI: $10.1016 /$ j.ijfatigue.2018.03.028.

[41] Correia, J., Apetre, N., Arcari, A., De Jesus, A., Muñiz-Calvente, M., Calçada, R., Berto, F., Fernández-Canteli, A. (2017). Generalized probabilistic model allowing for various fatigue damage variables, International Journal of Fatigue 100, pp. 187-194. DOI: 10.1016/j.ijfatigue.2017.03.031.

[42] Ferro, P., Lazzarin, P., Berto, F. (2012). Fatigue properties of ductile cast iron containing chunky graphite, Materials Science and Engineering A, 554, pp. 122-128. DOI: 10.1016/j.msea.2012.06.024.

[43] Berto, F., Gallo, P., Lazzarin, P. (2014). High temperature fatigue tests of un-notched and notched specimens made of 40CrMoV13.9 steel. Materials and Design, 63(1), pp. 609-619. DOI: 10.1016/j.matdes.2014.06.048.

[44] Berto, F., Lazzarin, P., Wang, C.H. (2004). Three-dimensional linear elastic distributions of stress and strain energy density ahead of V-shaped notches in plates of arbitrary thickness. Int. J. Fracture, 127(3), pp. 265-282.

DOI: 10.1023/B:FRAC.0000036846.23180.4d.

[45] Berto, F., Lazzarin, P., Kotousov, A. (2011). On higher order terms and out-of-plane singular mode. Mechanics of Materials, 43(6), pp. 332-341. DOI: 10.1016/j.mechmat.2011.03.004.

[46] Berto, F., Lazzarin, P. (2013). Multiparametric full-field representations of the in-plane stress fields ahead of cracked components under mixed mode loading, International Journal of Fatigue, 46, pp. 16-26.

DOI: 10.1016/j.ijfatigue.2011.12.004.

[47] Wu, W., Hu, W., Qian, G., Liao, H., Xu, X., Berto, F. (2019). Mechanical design and multifunctional applications of chiral mechanical metamaterials: A review, Materials and Design, 180, 107950. DOI: 10.1016/j.matdes.2019.107950

[48] F. Berto, E. Barati. Fracture assessment of U-notches under three point bending by means of local energy density. Materials \& Design 32 (2011), 822-830. DOI: 10.1016/j.matdes.2010.07.017.

[49] S.M.J. Razavi, P. Ferro, F. Berto, J. Torgersen. Fatigue strength of blunt V-notched specimens produced by selective laser melting of Ti-6Al-4V. Theoretical and Applied Fracture Mechanics 97 (2018) 376-384.

DOI: $10.1016 /$ j.tafmec.2017.06.021. 